\title{
إيقاع الخبر والإنشاء في شعر مفدي زكرياء
}

$$
\begin{aligned}
& \text { أ ـ عبد الحميد بوفاس الأس } \\
& \text { قسم الآداب و اللَّة العربية } \\
& \text { جامعة الإخوة منتوري } \\
& \text { قسنطينة }
\end{aligned}
$$

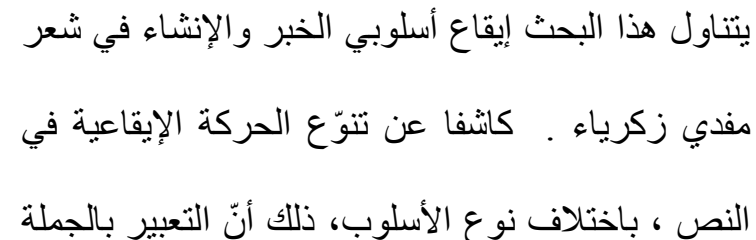

$$
\begin{aligned}
& \text { الخبرية يختلف - من دون شك - عنه بالجملة الإنشائية ، } \\
& \text { لتتعدد بذلك إيقاعات هذه الأخيرة كاثفة عن روح } \\
& \text { حوارية تتلون فيه النغمة الصوتية المعبّرة عن النشاط } \\
& \text { الانفعالي و النفسي من جهة ، وتساؤلات العقل، من جهة }
\end{aligned}
$$

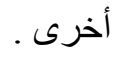

\section{Abstract:}

إن الظاهرات الإيقاعية تنتوع لتوبرة

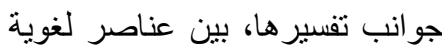

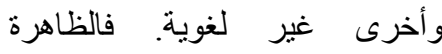
الإيقاعية تتصل بمختلف علوم اللغة،

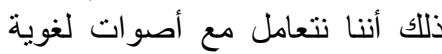
واردة وفق تتظيمات مخصوصة. كما أنّ اللغة هي الوسيلة التعبيرية الأكثر إفصاحا عن رؤى وتصور الحنية التعيرية

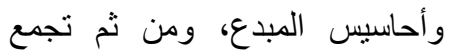
اللغة الإنسانية في الفن بين الرؤية و التنكيل الإبداعي.
The present research deals with the rhythm of the predicative and affective styles within Moufdi Zakarya's poetry. It attempts to reveal the diversification of the rhythmic movement within the text depending on the sentence system or structure since the expression using the declarative sentence is undoubtedly different from using the affective one, leading to numerous rhythms of the latter and revealing a dialogic spirit in which the phonemic note is coloured to express emotional and psychological activity from the one hand, and the queries of the mind from the other. 


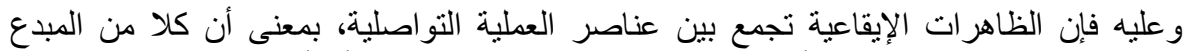

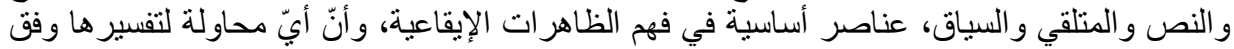

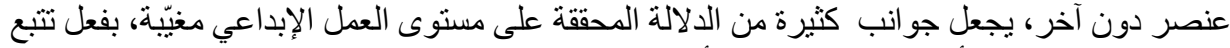

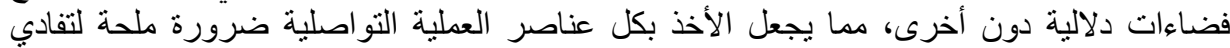

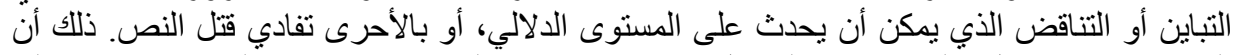

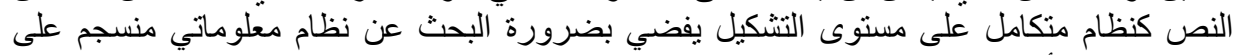
مستوى الرؤية أيضا.

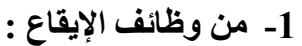

ومن دون شك ، فإنّ الظاهرات الإيقاعية ظاهرات معقدّة ومتشابكة ومتداخلة ، باعتبار ها نثاطا إنسانيا،

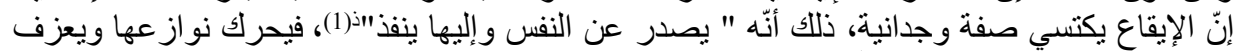

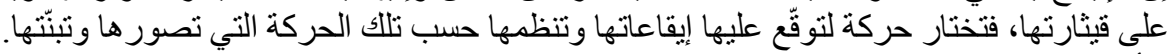

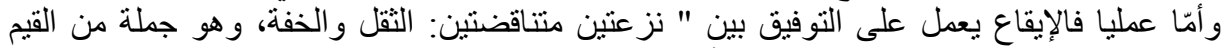

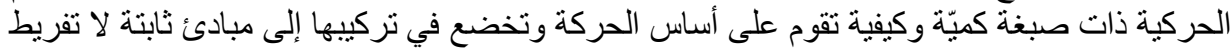

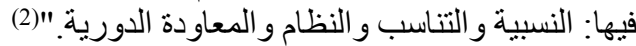

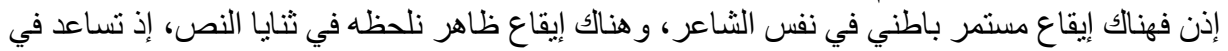

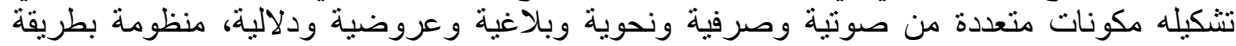

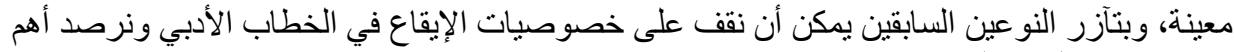

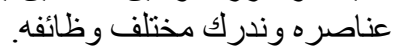

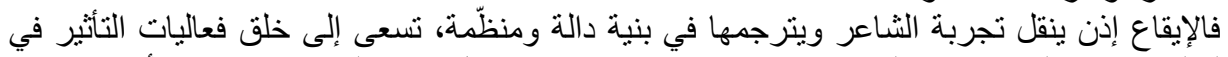

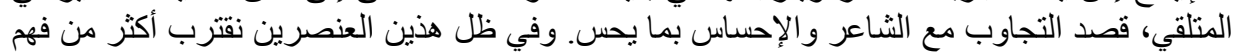

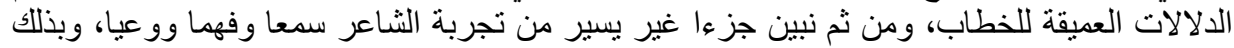

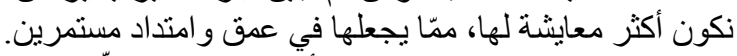

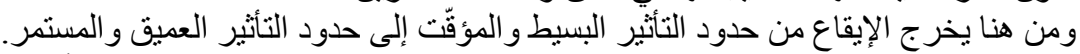

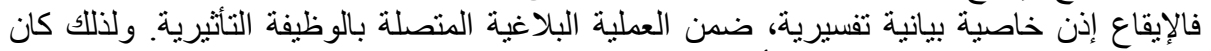

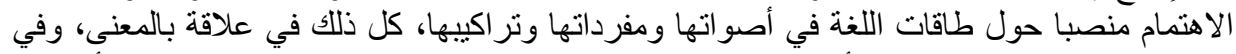

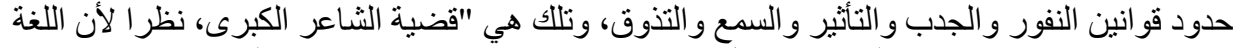

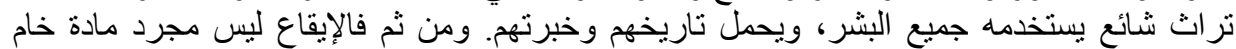

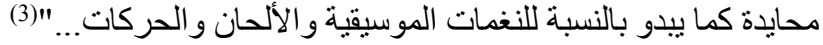

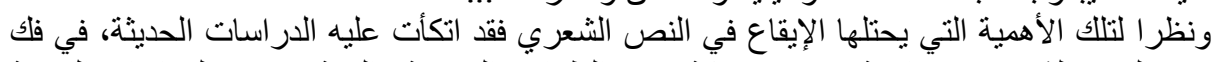

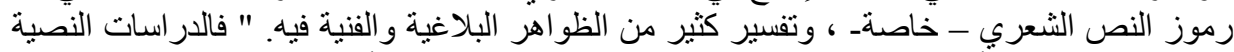

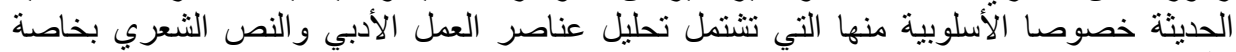

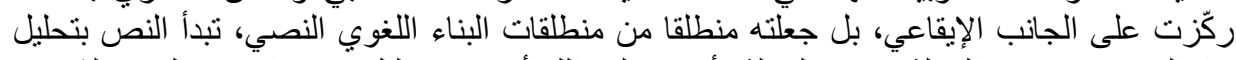

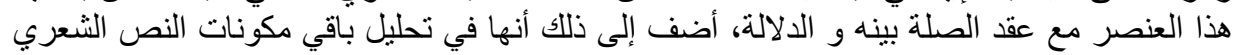

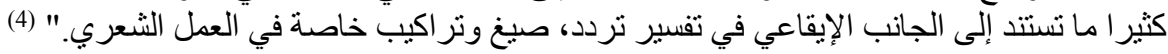

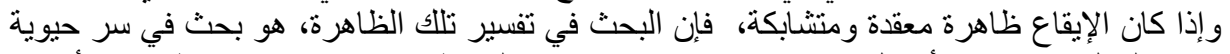

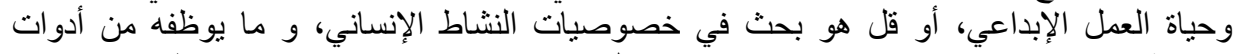

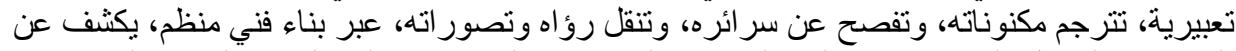

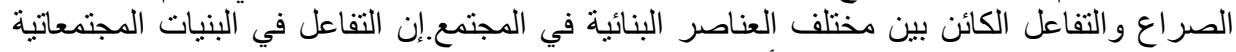

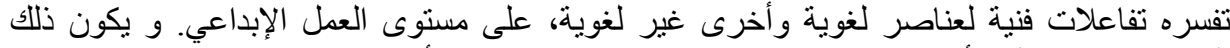

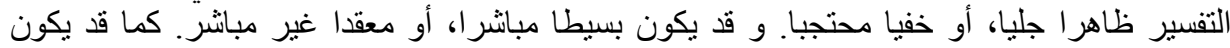
أحادي العناصر و العلاقات، أو متعددها ومتنو عها. 
و عليه فان الحديث عن الإيقاع في الثعر لا يمكن أن يتصور بمعزل عن صاحبه، أو وسيلة التعبير

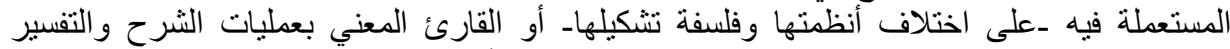

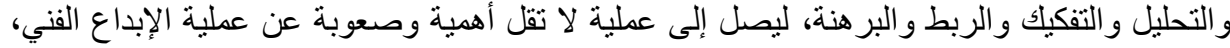

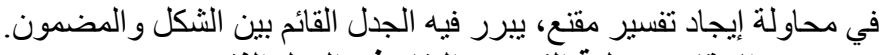
2- الإيقاع وعملية النسيج والبناء في العمل الفني :

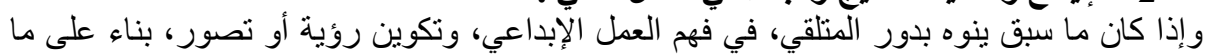

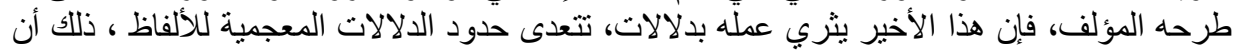

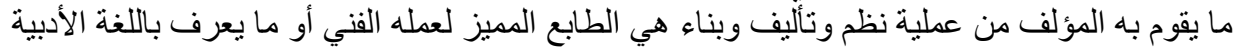

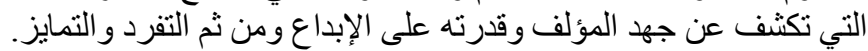

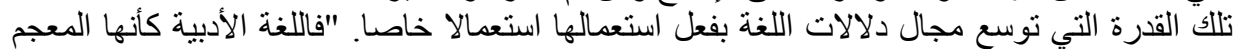

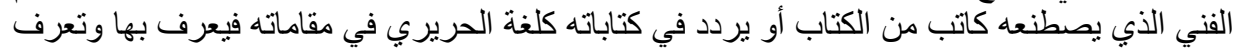

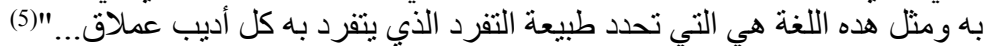

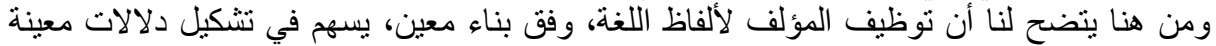

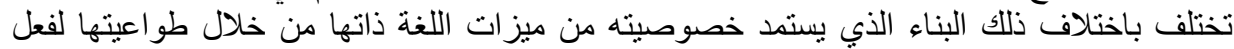

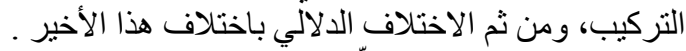

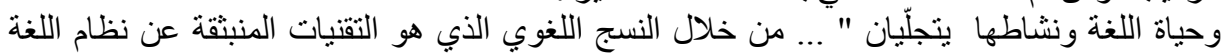

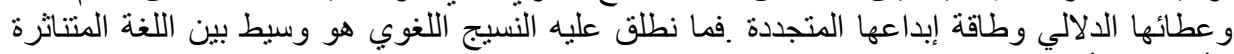

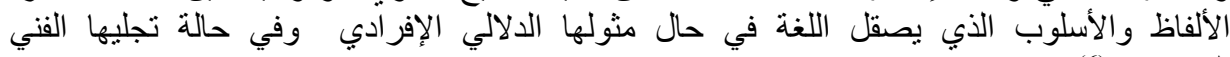

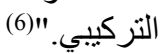

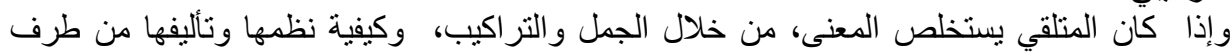

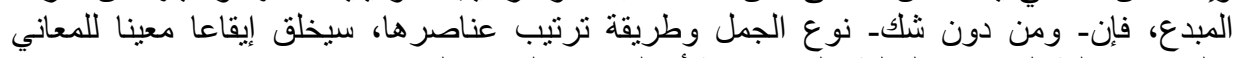

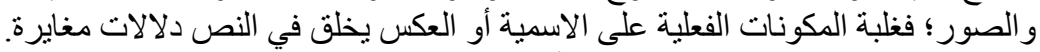

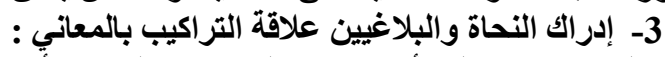

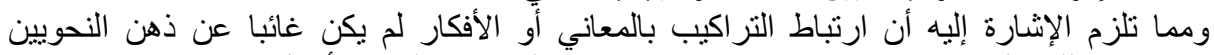

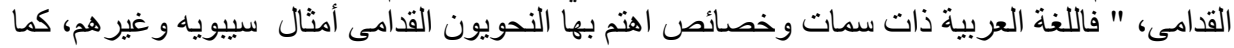

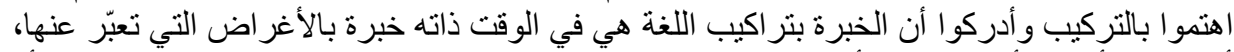

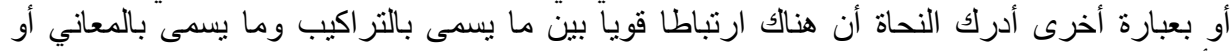

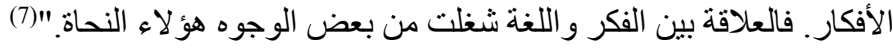

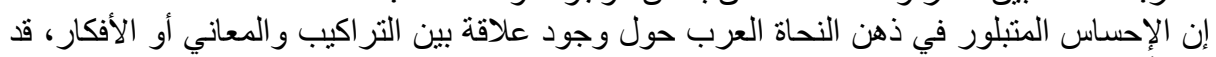

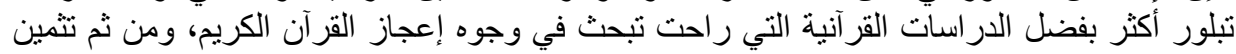
النظرة السابقة للنحو العربي.

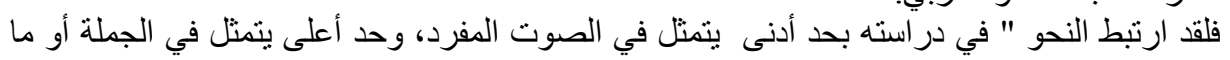

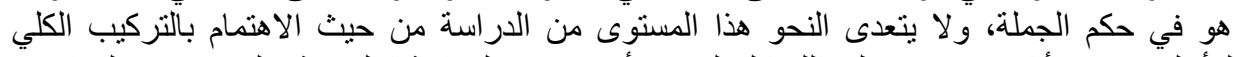

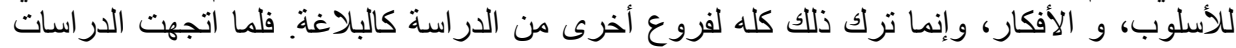

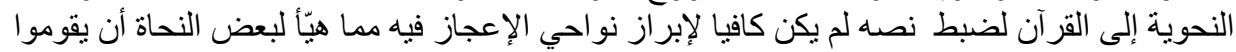

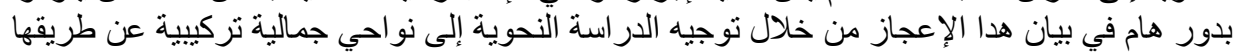

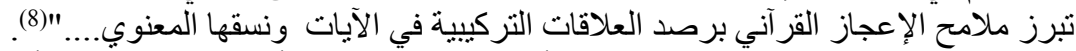

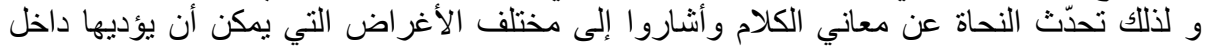

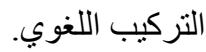

ويوسّع (عبد القاهر الجرجاني) النظرة السابقة، بفضل جهوده الجبارة والمبكرة في ميدان الدلالة النالة

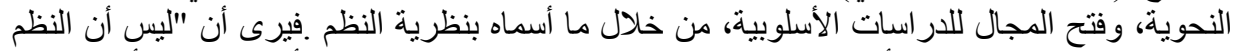

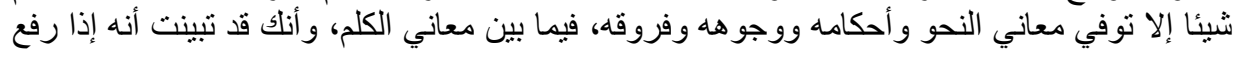




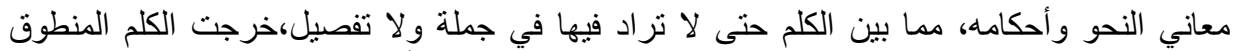

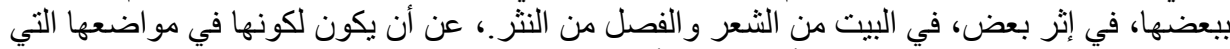

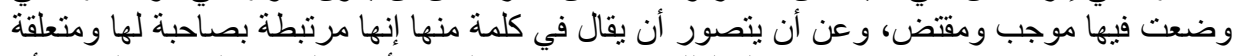

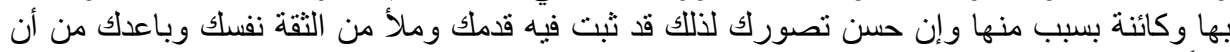

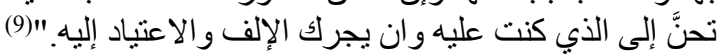

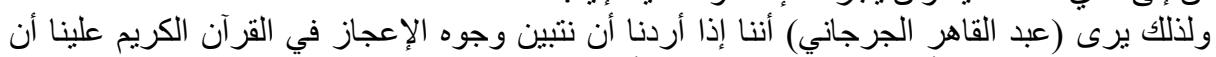

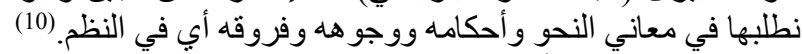

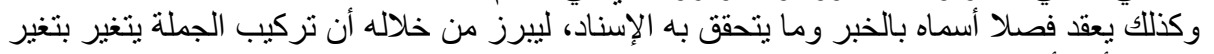
المعاني؛ أب أن "المعنى الثنابت في العقول والقائم في النفوس هو لهو الذي وراء التغيير في نظام

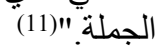

من هنا تتضح لنا العلاقة الرباعية الأبعاد التي حقتنها دراسات عبد القاهر الجرجاني في تفهم وجوه

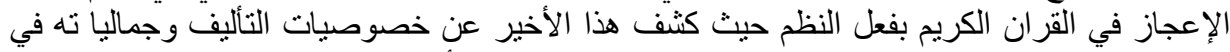

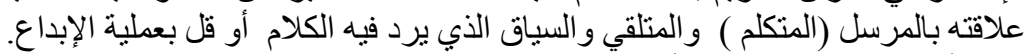

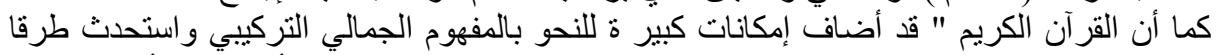

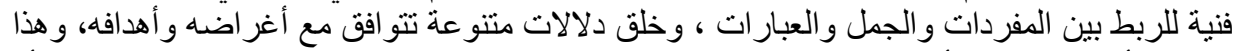

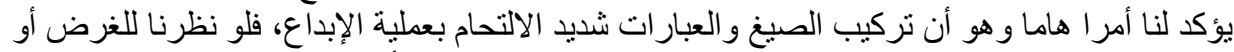

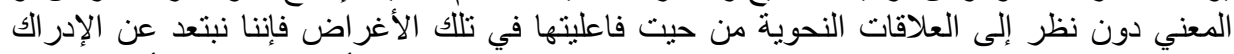

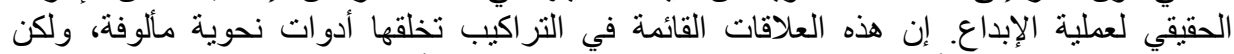

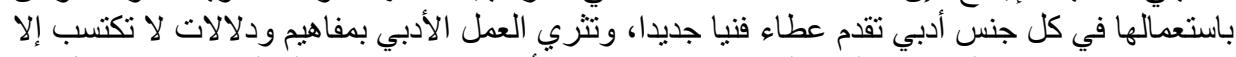

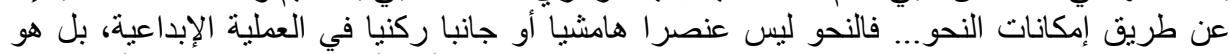

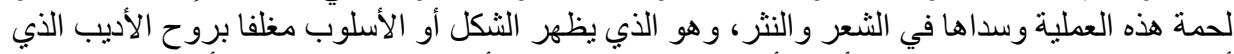

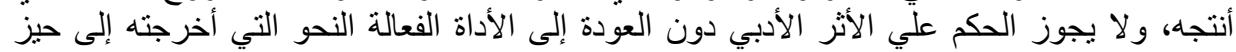

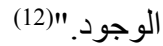

إن العلاقات التي أثرنا إليها سابقا، هي من صميم عملية التواصل اللغوي، وبذلك شكلت نظرية النظم

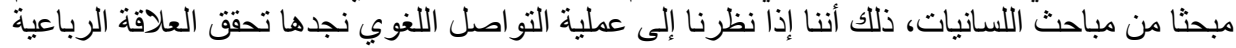

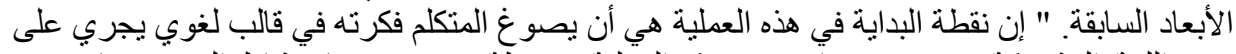

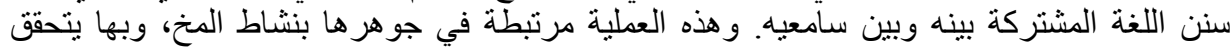

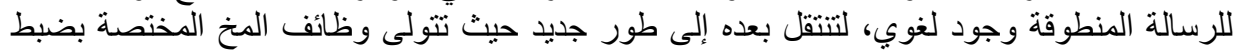

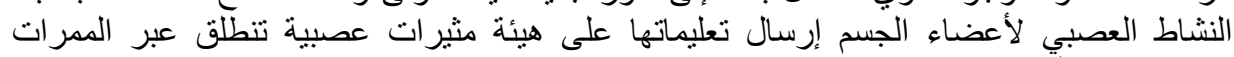

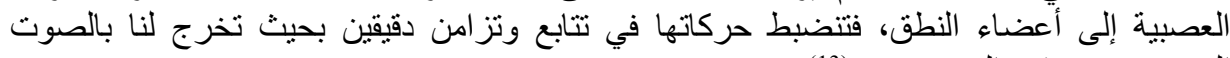
الصحيح في موقعه الصحيح... "(13).

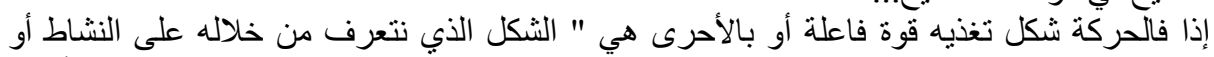

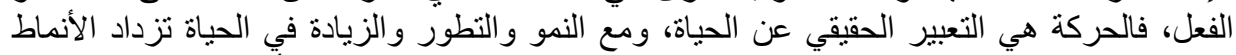

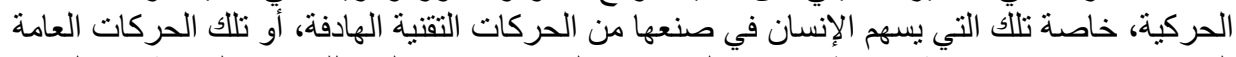

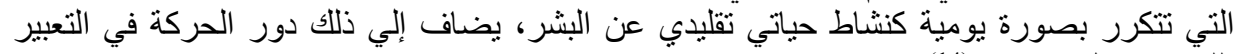

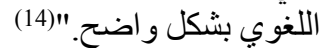

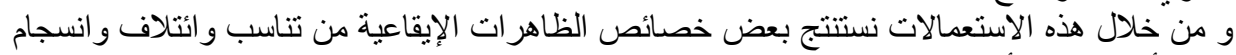

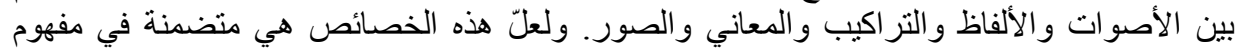

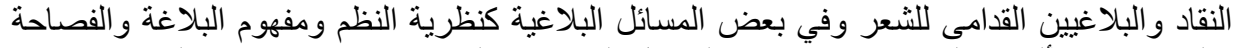

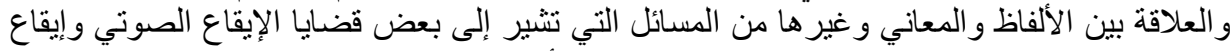

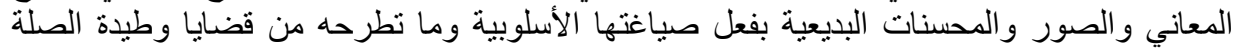




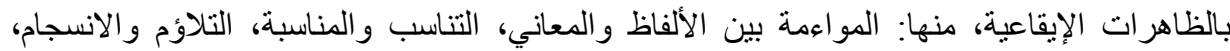

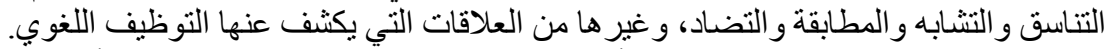

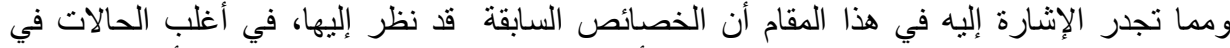

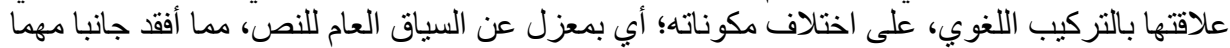

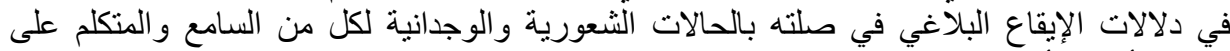
مسنوى أوسع؛ أي النص.

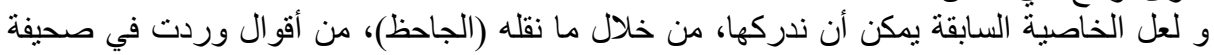

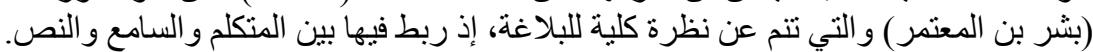

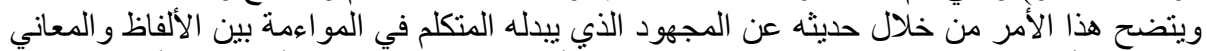

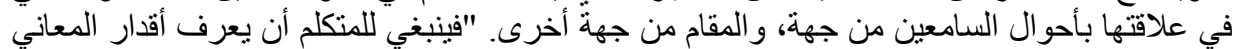

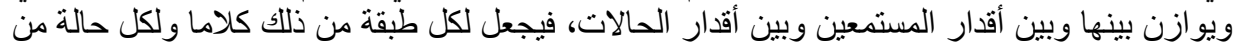

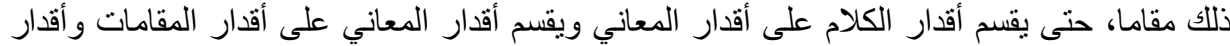

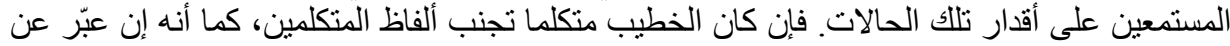

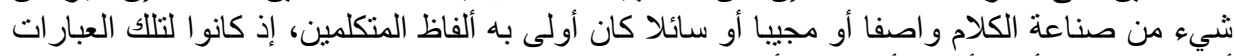

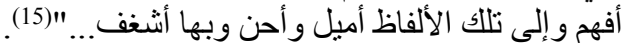

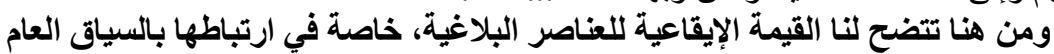

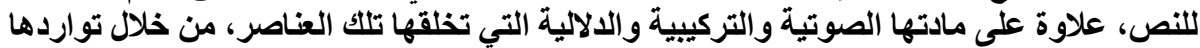

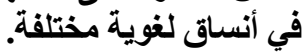
وعلى هذا الأساس فإن "الكيفية التي تثثكل بهان الظها الظواهر الأسلوبية والبلاغية داخل

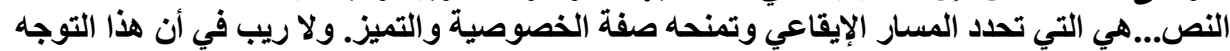

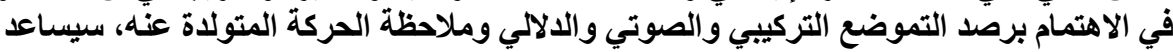

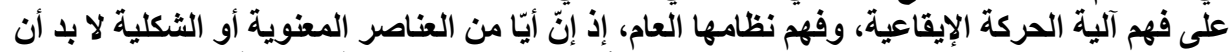

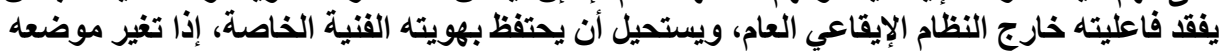

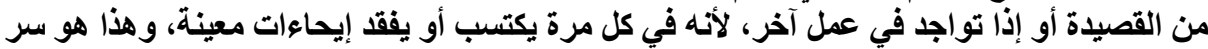

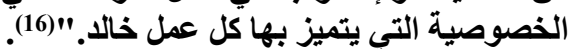

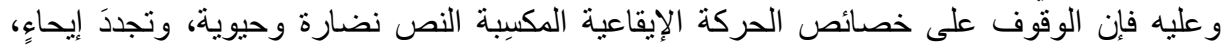

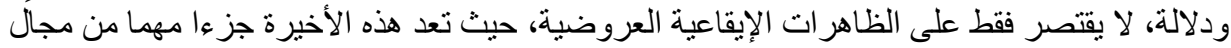
و واسع، يجمع بين علوم متعددة.

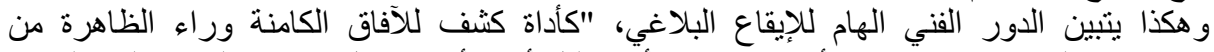

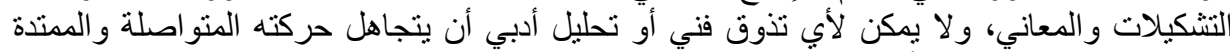

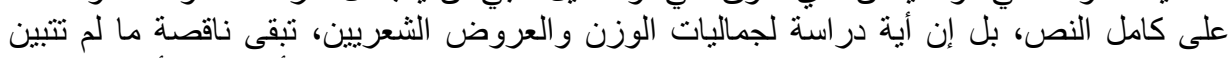

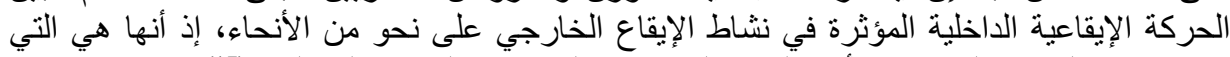

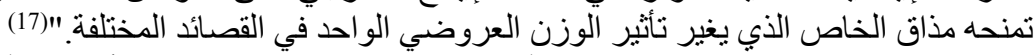

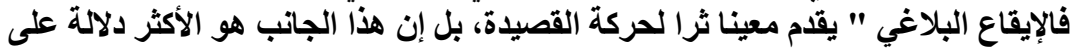

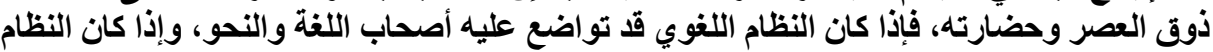

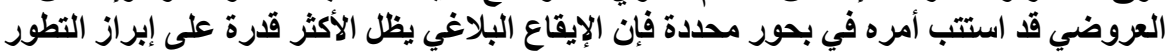

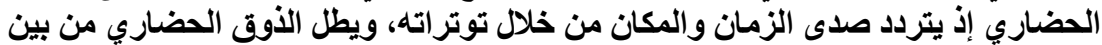
أوتاره." (18).

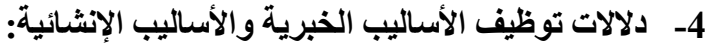
ومما هو ملاحظ في الثعر العربي القديم كثرة توظيف الأساليب الإلئية الخبرية مقارنة بالإنشائية ، وربّما يعود ذللك إلى " غلبة الموضوعات التي تضع الثاعر في موقف المخبر عن حاله، أو عن حال غيره، إلا أنّ 


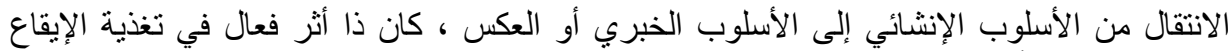

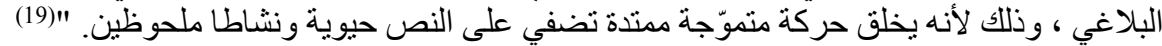

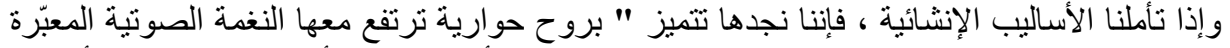

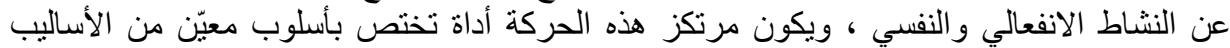

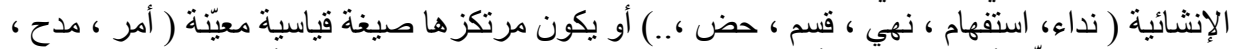

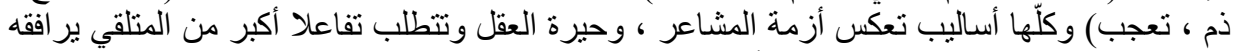

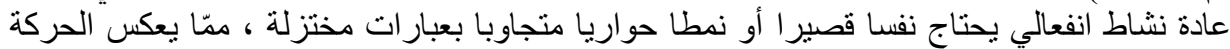

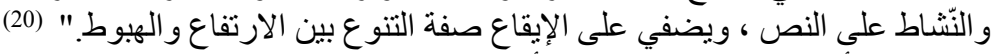

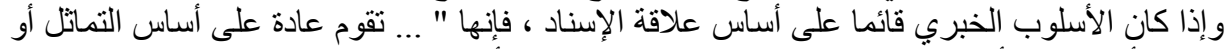

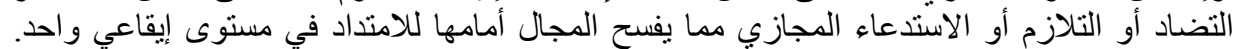

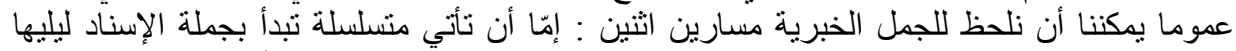

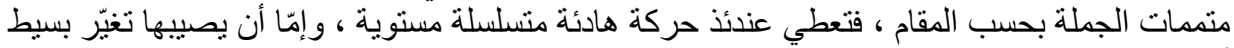

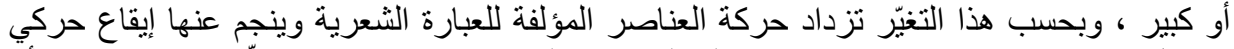

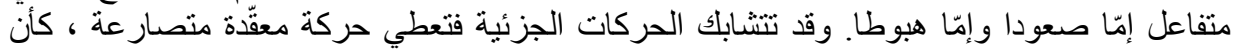

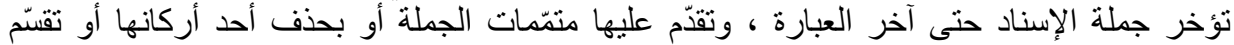

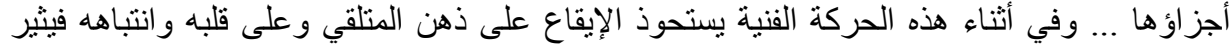
تفاعله ويوقظ إحساسه." (21)

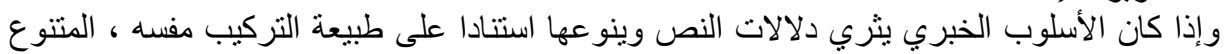

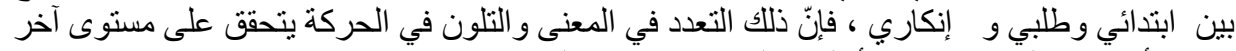

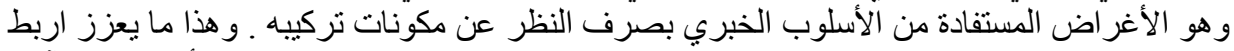
التراكيب بالسياق الواردة فيه ، ويكثف دلالات النص من خلال الانتقال من معنى أصلي إلى آلى آخر

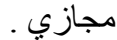

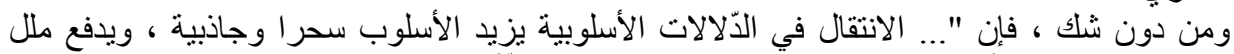

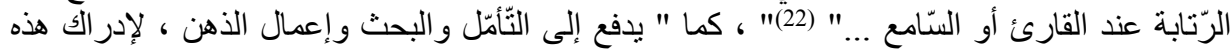

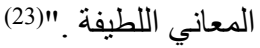

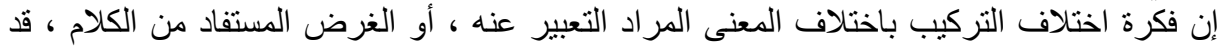

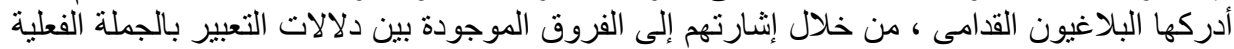

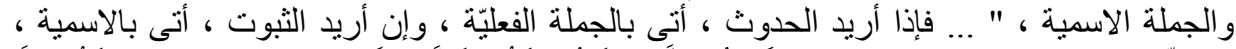

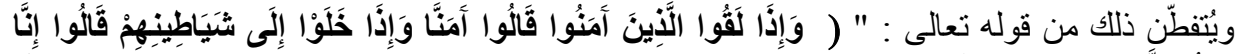

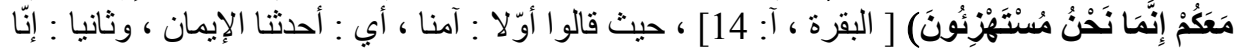

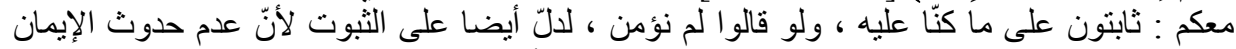

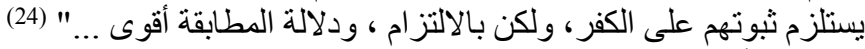

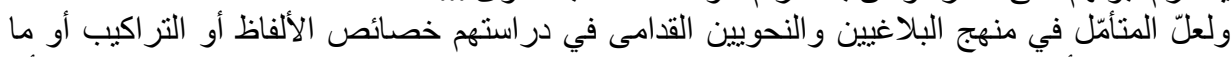

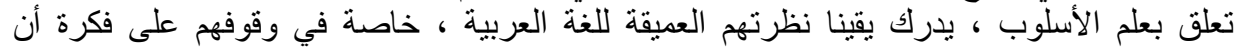

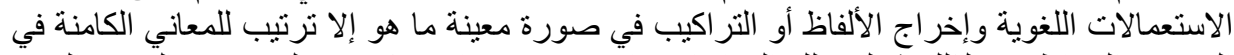

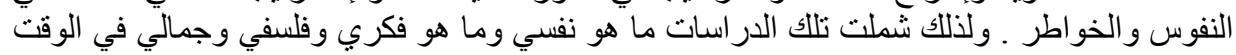

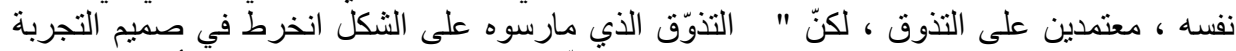

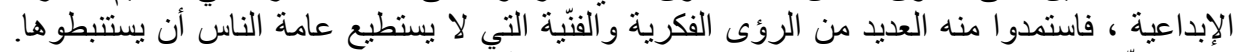

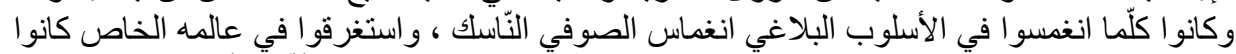

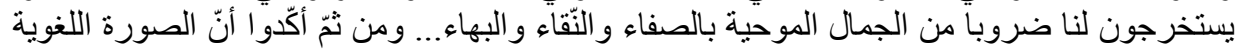
البلاغية لبست مجرّدة ؛ بل هي صورة تعيش في عالم الحياة ، وتستجيب على الدّو ام لكل انفعال ، ولكل الكل 
فكر ، فظلّت أعمالهم خالدة حيّة في وجداننا ووجدان الدارسين الغربيين المنصفين الذين اعترفوا لهم

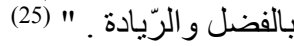

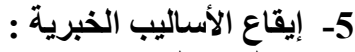
قصبدة الذبيح الصناعد:

نظمت بسجن بربروس في القاعة التاسعة في الهزيج الثاني من الليل أثناء تنفيذ حكم الإعدام على

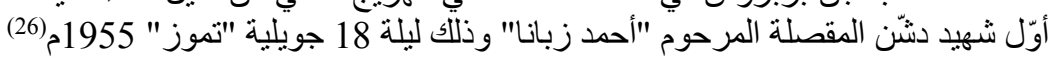

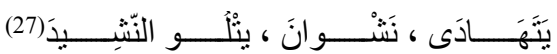

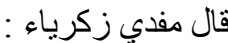

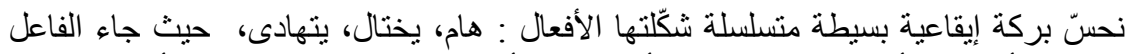

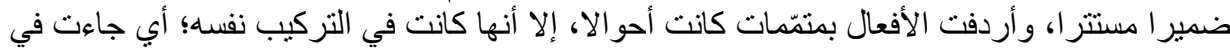

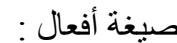

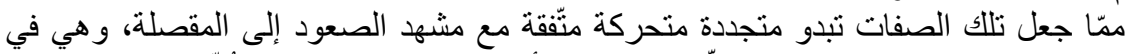

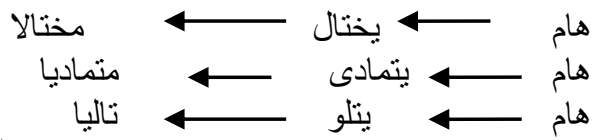

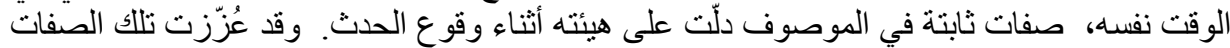

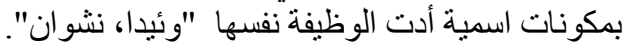

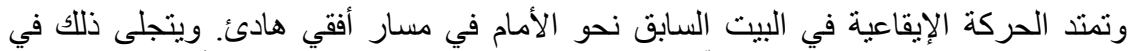

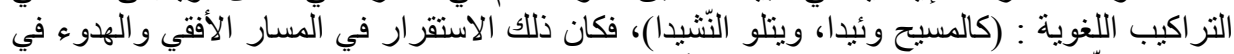

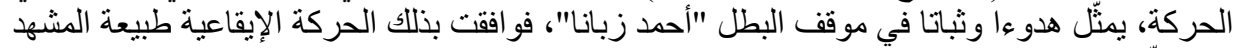
الذي دلّت عليه الدكونات الفعلية والاسمية. وشبيه بالحركة الإيقاعية السابقة، نحس إيقاعيا مماثنا مع بعض الاختية الإنلافات الطفيفة التي شكّاتنها خصوصيات تركيب الجمل، يقول الثناعر في القصبيدة نفسها:

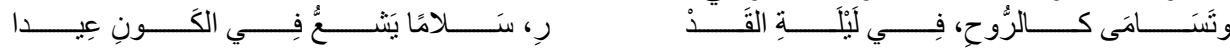

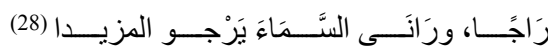

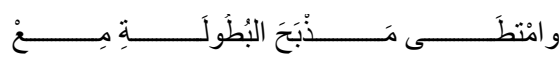

حيث نحس بحركة إيقاعية بسيطة في البيث الثعري الأوّل ممّا سبق ، في قول الثشاعر (وتسامى)

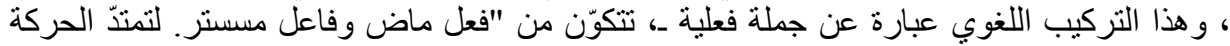

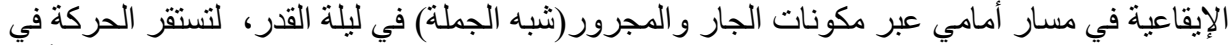

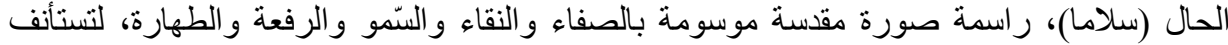

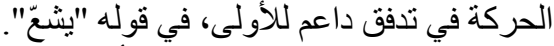

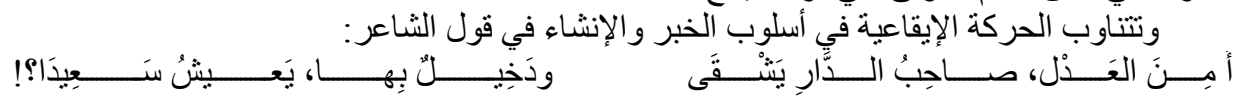

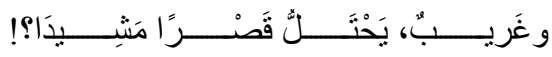

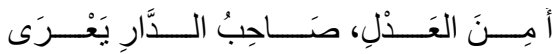

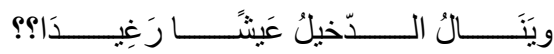

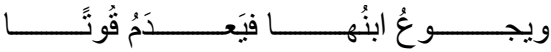

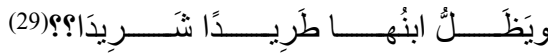

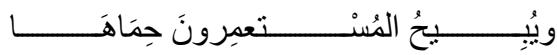




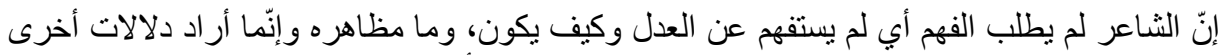

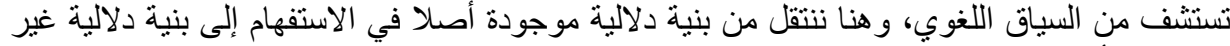

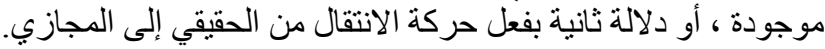

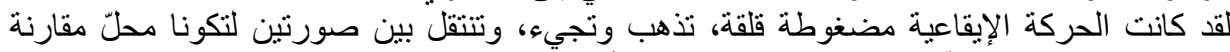

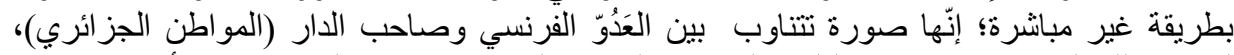

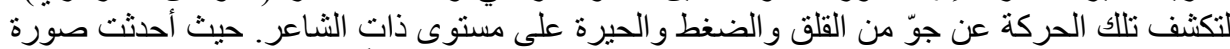

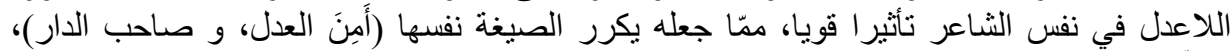

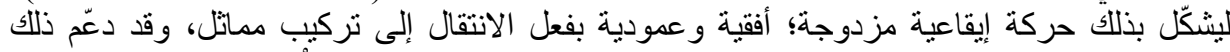

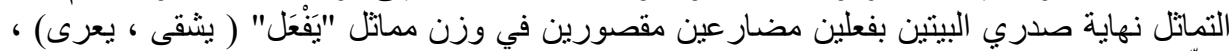

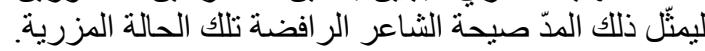

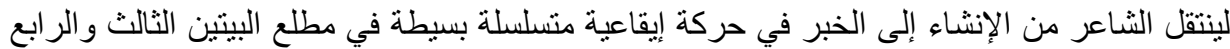

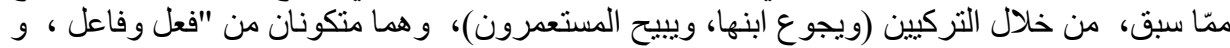

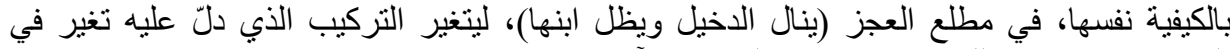

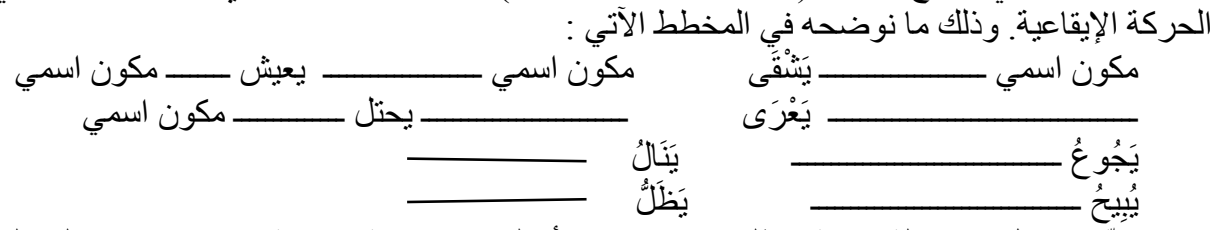

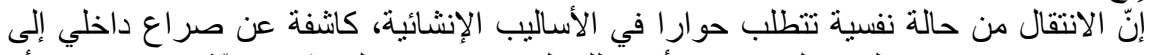

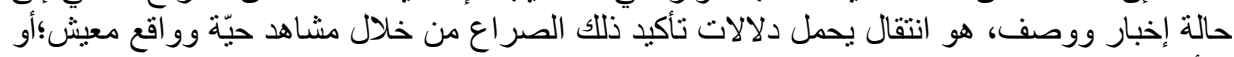
بالأحرى واقع مرير معوّض تلآك الحركة النفسية. ويقول الثاعر في قصبيدة "وتعطلت لغة الكلام":

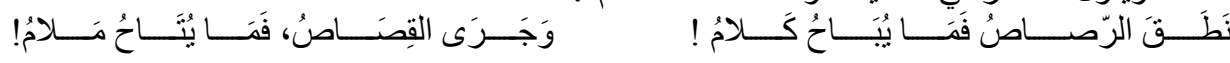

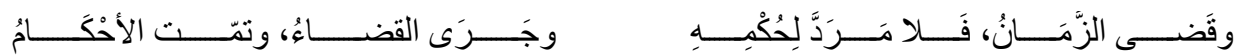

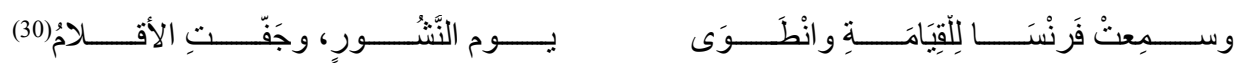

نحس بحركة إيقاعية متسلسلة، شكّلتها نسبة التركيب "فعل وفاعل"

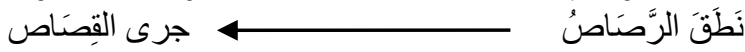

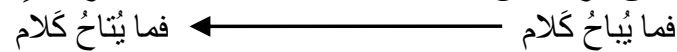

نلاحظ التوازن في مكونات التر اكيب على مستوى الأبيات الثلاثة:

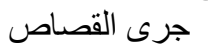

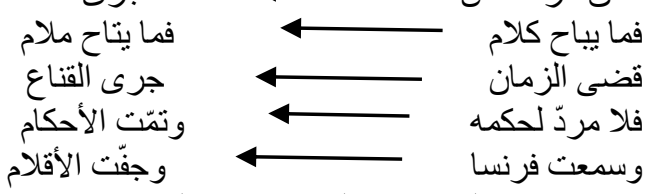

كما أسهوت بعض فض الظاهرات البلاغية في خلق انسجام صوتي شكّله السجع بين الرصاص والقصاص وكوا جناس في الوقت نفساه.

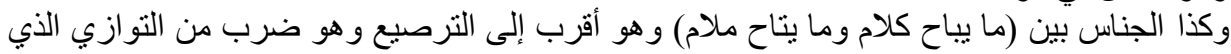

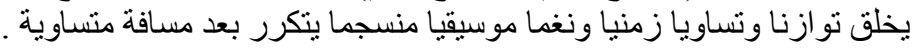


أضف إلى ذلك النطريز البلاغي وهو ضرب من التوازن أيضا في التركيب و الصيغ الصوتية، وذلك

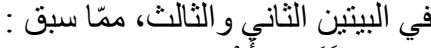

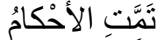

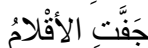

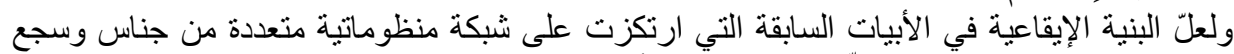

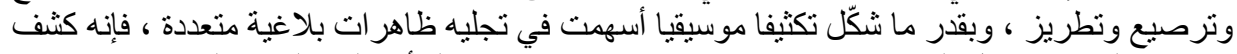

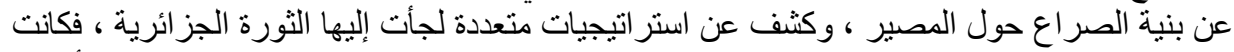

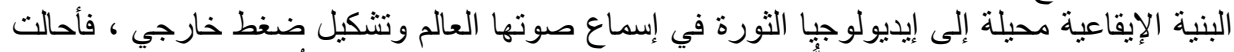

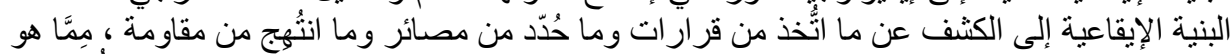

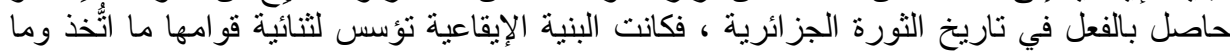

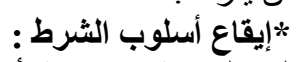

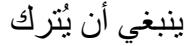

وتتجلى الحركة الإيقاعية أكثر في أسلوب الثرط القائم على جملتين، جملة فعل الثرط وجواب

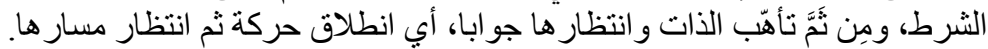

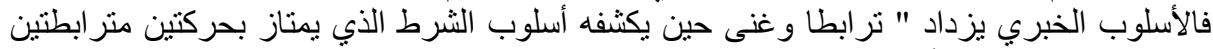
ومتقابلتين في آن معا، الأولى منها تتصاعد في فعل الثرط، و الثانية تهبط مع جو ابه حيث يصل الإيقاع

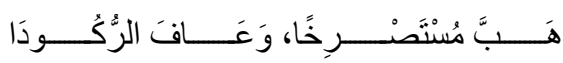

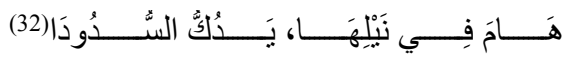

من ذلك قول الثناعر:

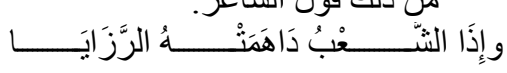

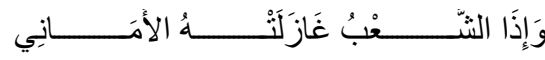

فقد بدأ الإيقاع قويا مرتكزا في أداة الظرف (إذا)، ليصعد في جملة فعل الثرط (الثعب داهيته

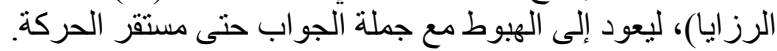

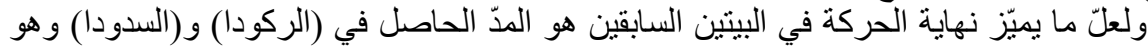

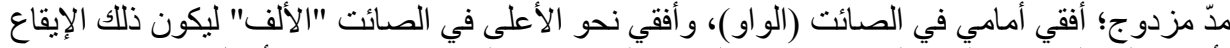

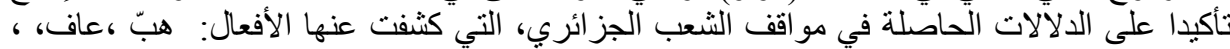

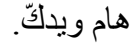

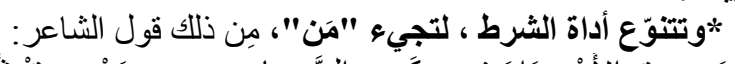

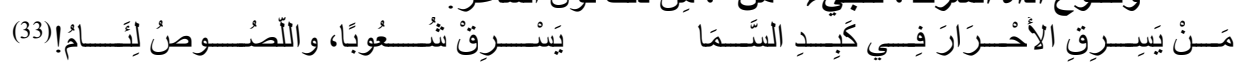

يبدأ البيت بايقاع منوثّر في حركة منصاعدة تتطلّع إلى أفق يبحث عن الاستقر ار والراحة، كما هو

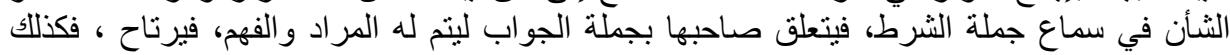

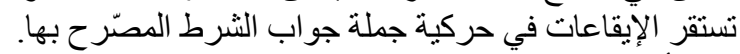

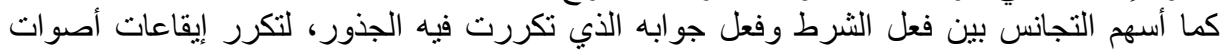

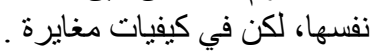

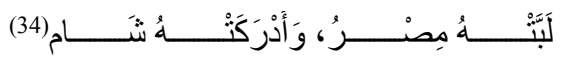
*وقد تجيء الأداة إنْ، كما في قول الثناعر:

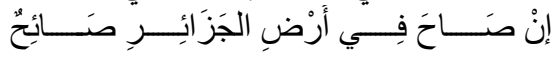

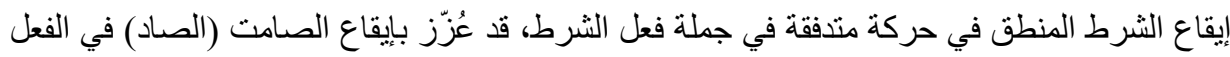
"صاح"، و الفاعل "صائح"، وكذلك في كلمة "مصر في في جملة جو اب الثرط. 


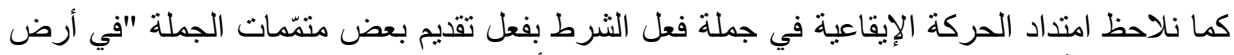

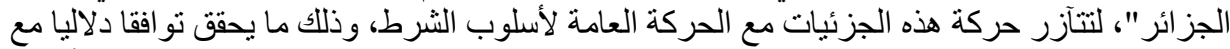

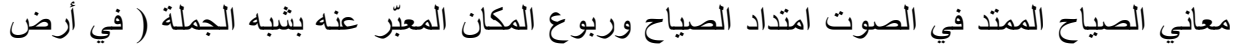

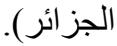

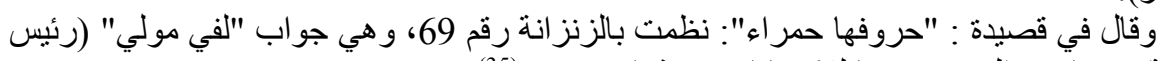

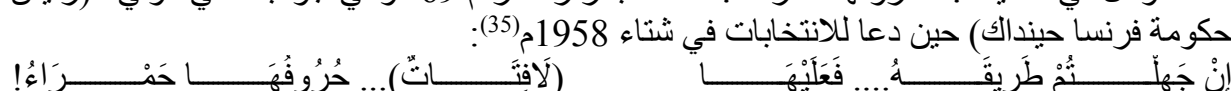

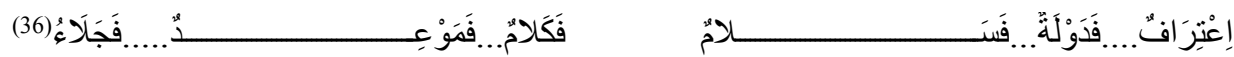
تتدفق الإيقاعات في حركة أمامية متسار عة وقد انسجمت دلاليا مع خصوصيات بلاغية وأخرى نحوية،

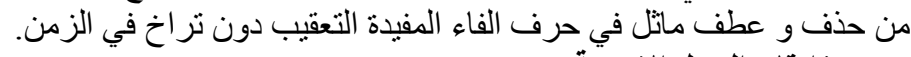

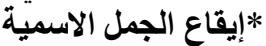

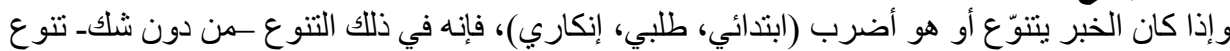
دلالي يكثف عنه خصوصية التركيب الذي يؤدي اختلافه إلى اختلاف الدانلانلة المحققة على مستوى

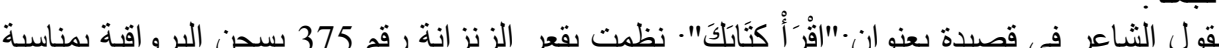

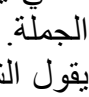

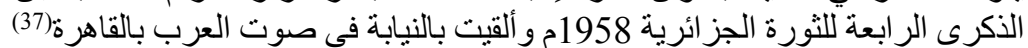

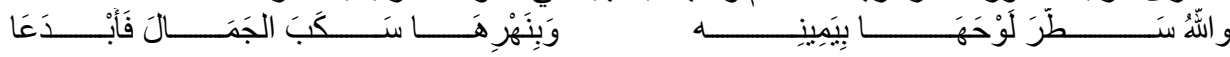

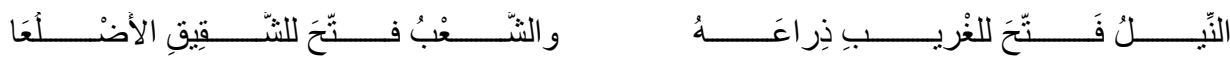

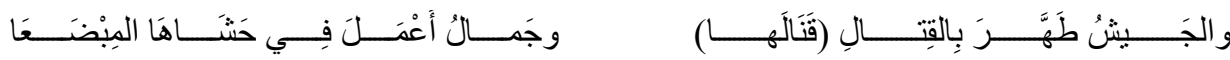

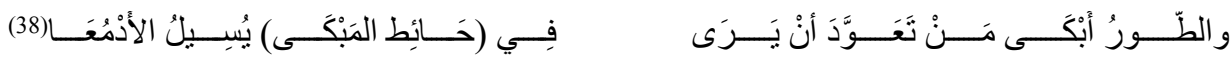
إيقاعات جمل اسمية مبدو عة بأسماء خبر ها جمل فعلية، توز عت في خطاطة هندية تكاد تكون متساوية: الله سطرّ النيل فتّح

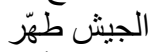

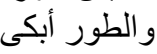

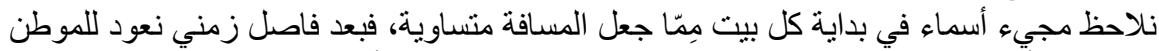

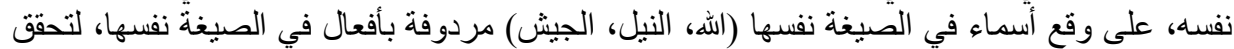

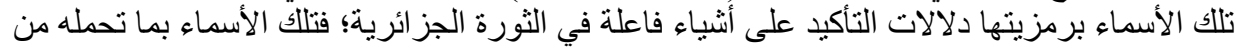

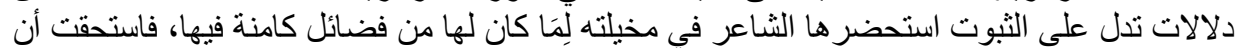

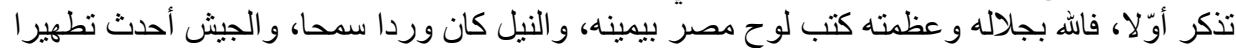
وتصفية للاستعمار الإنجليزي، و جبله الطيله الطور أسال دموعا.

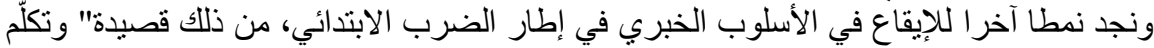

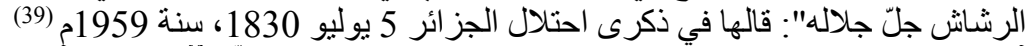

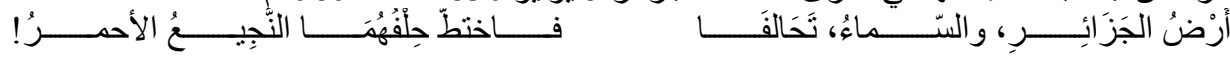

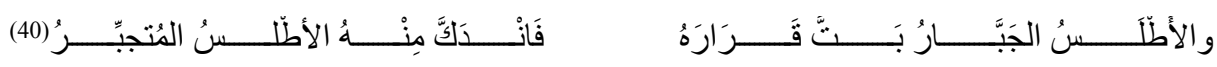


()

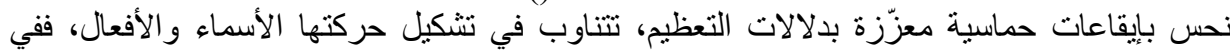
الجمل الخبرية الاسمية التي خبرهاء ها جملة فعلية نحس تصأعد الحركة الإيقاعية لتسنقل في الجمل

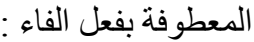

$$
\begin{aligned}
& \text { أرض الجزائر و السماء تحالفا }
\end{aligned}
$$

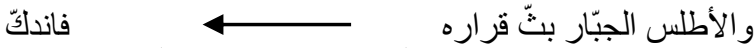

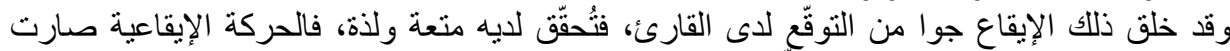

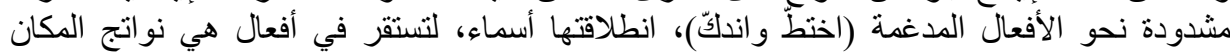
(أرض الجز ائر و الأطلس الجبّار)، إنه انتقال من الثبوت إلى الحثل الحدوث.

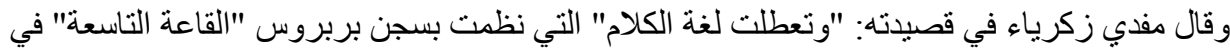

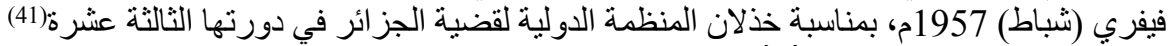

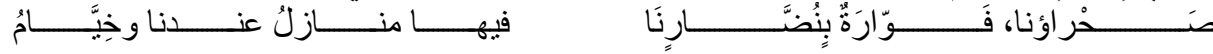

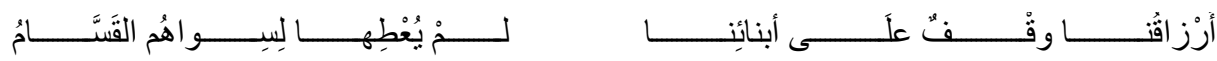

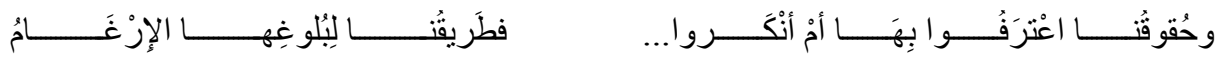

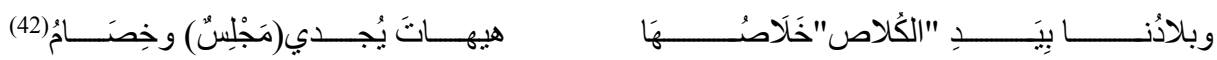

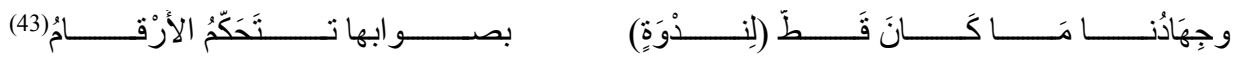

نحس بحركة إيقاعية مرتفعة وفيها نبرة حادة كثفت عنها الأسماء صحراء- أرزاق-حقوق- بلادـ

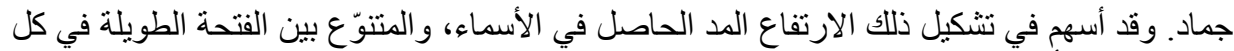

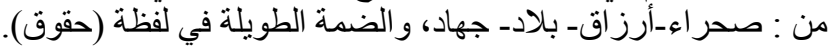

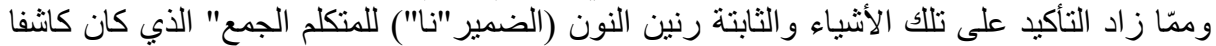

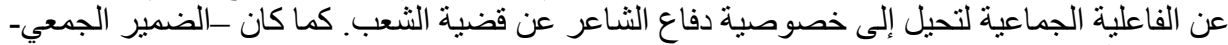

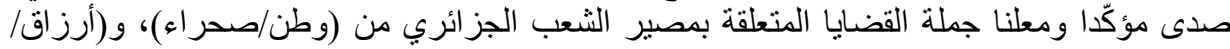
مصدر قوت) وحقوقه و كل ما تحمله من معنى، و و(جهاد /كفاح) و واستعماله "مشرو عية الرئة الجهاد".

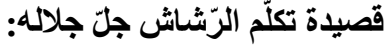

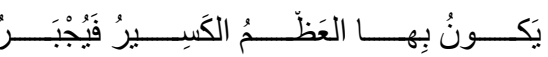

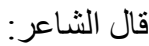

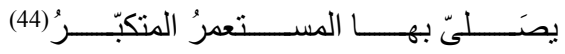

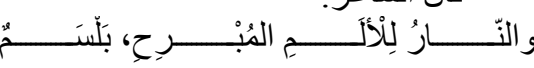

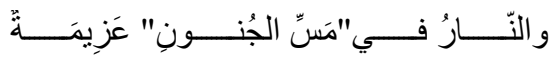

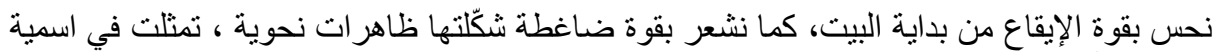

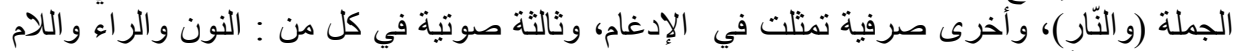

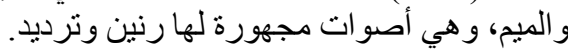

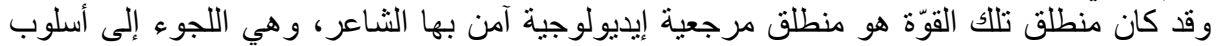

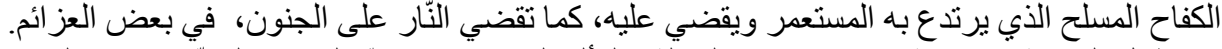

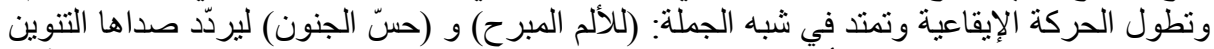

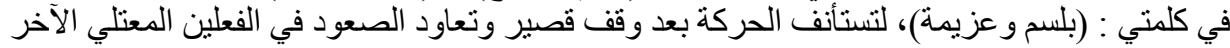


(يكوى، يصلى)، و الجار و المجرور (بها)، لتستمر من جديد، موحية بضرورة استمرار النار ( الكفاح

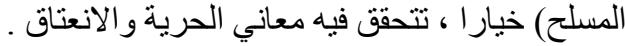
وقال في القصيدة نفسها:

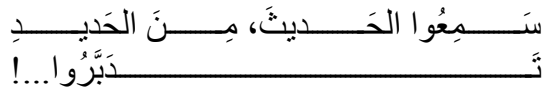

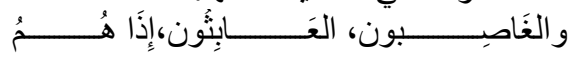

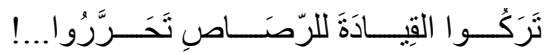

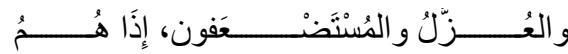

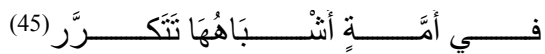

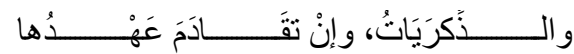

نحس بحركة إيقاعية ممتدة نحو الأمام، وقد جانستها الصيغ الصرفية (اسم الفاعل وجمع المذكر السالم)

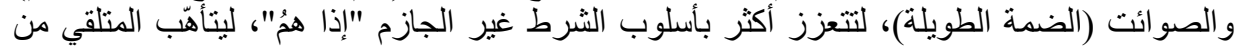

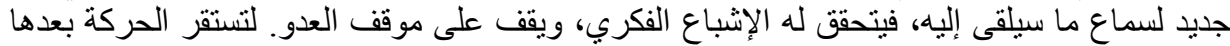

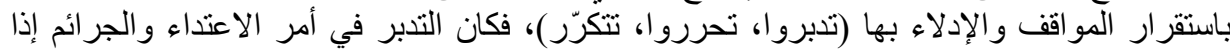

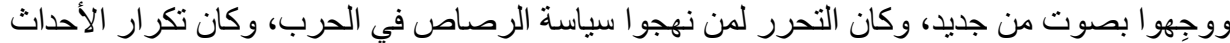

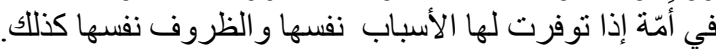

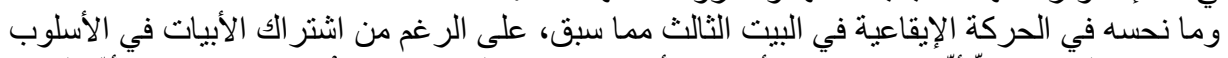

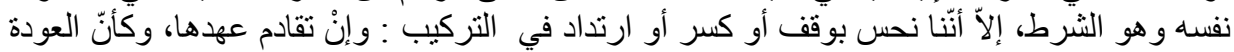

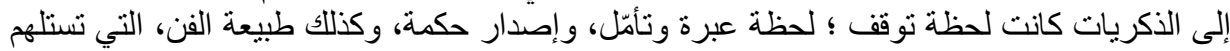

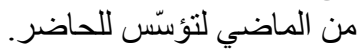

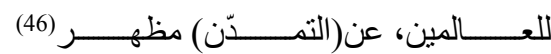
وقال في القصيدة نفسها:

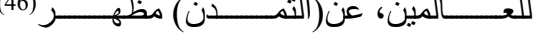

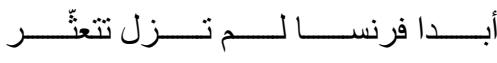

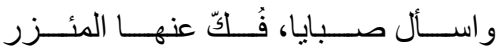

$$
\begin{aligned}
& \text { و انظـــــر إلـــــى الأحــــر ار، فيهـــــا تقبــــر }
\end{aligned}
$$

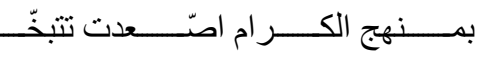

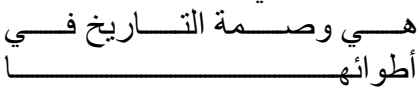

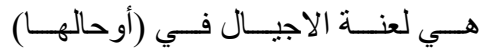

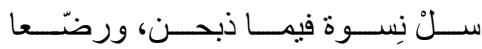

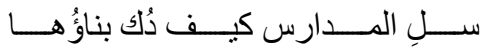

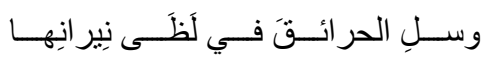

إلقاء ودفع الحركة الإيقاعية بفعل حركة الإشارة (هي وصمة/هي لعنة)، هي نقلة للمنلقي وسبح ليقف

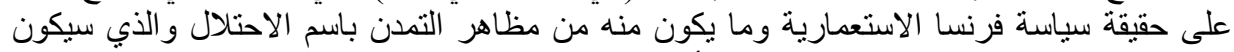

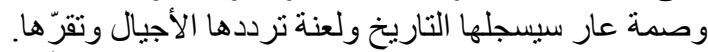

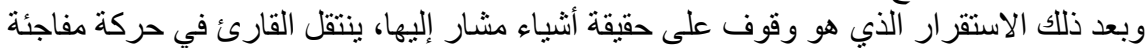

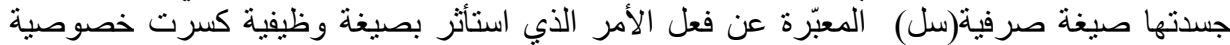

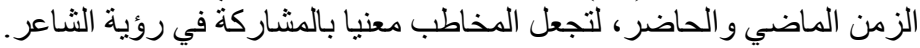

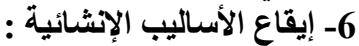

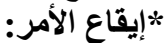
قصيدة "اعلمارد الاهز: الاسمر": 


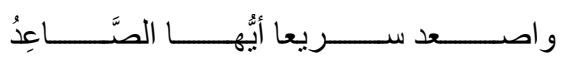

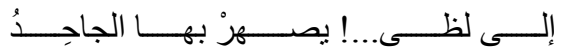

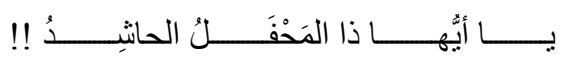

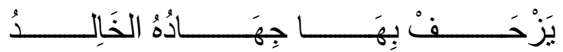

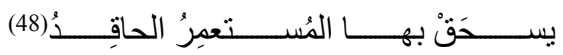

اصنـالْ:

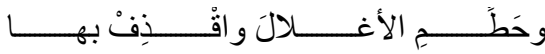

تقلالَ إفْرِقِيَ

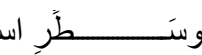

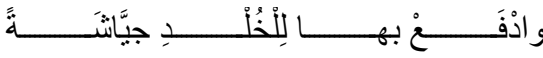

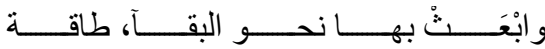

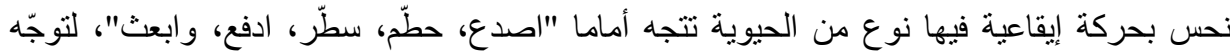

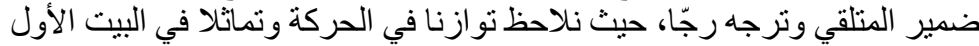

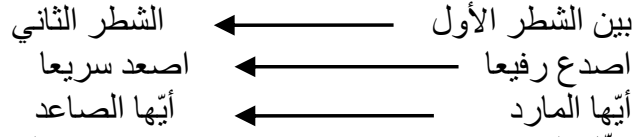

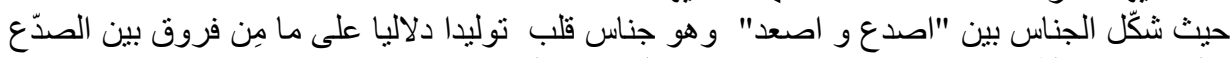

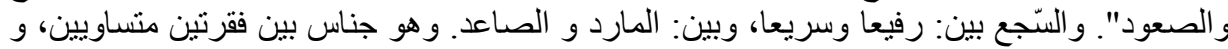

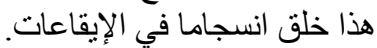
كما نلمس حركة إِيقاعية أخرى شكَّلتها أنظمة متنو عة للتركيب من ذلك:

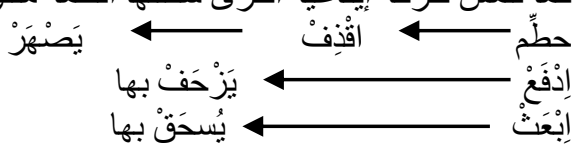

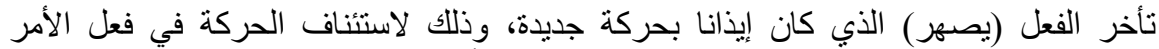
(اقذف)، بينما نلاحظ اقتر اب ذلك المرتكز إلى بداية عجز الأبيات لغياب العطف الذي كان كان استئنافا

وتجديدا للحركة، فكان ذللك حسب نظام الجملة (فعل الأمر وجو ابه)، كما هو الثأن في أسلوب الثربات الثرط.

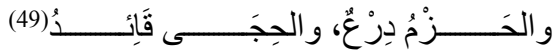

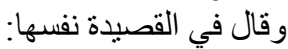

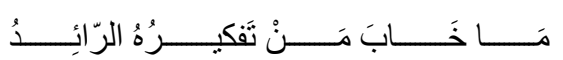

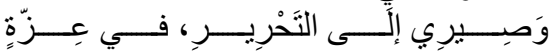

(50)占

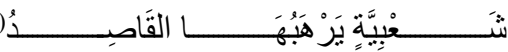

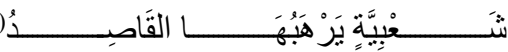

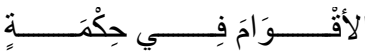
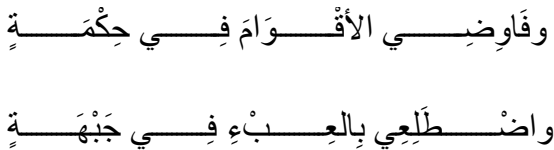

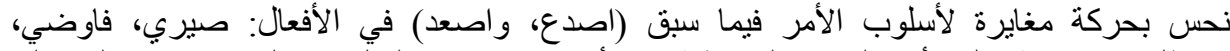

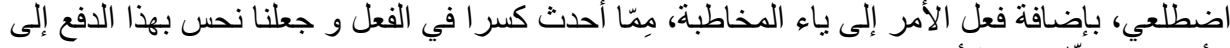
الأمام وقد شكّل حركة أخرى: سيري في عزة فيكي حركة فاوضي بحكمة فيرة في في في

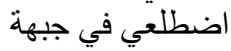
مما زاد في تجانس الإيقاعات بفعل شبه الجملة والتي كانت مكوناتها تحمل الصيغة الصرفية نفسها

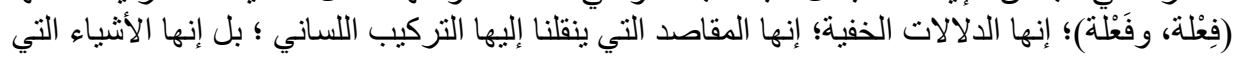


لم قلها الشاعر صر احة، وتلك هي طبيعة الفن بصفة عامة، والثّّعر بصفة خاصة، ينقلنا من أثياء قلناها

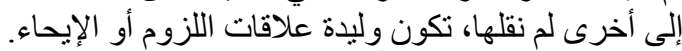

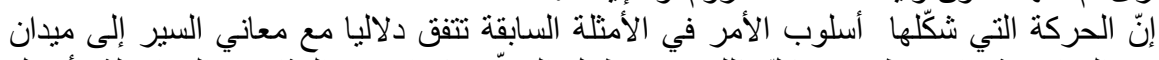

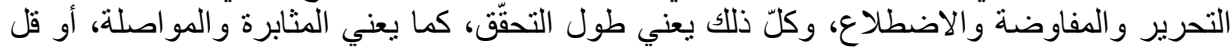

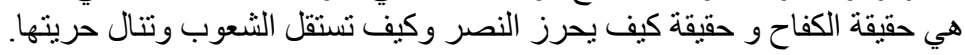

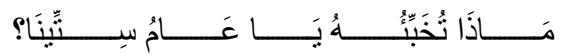

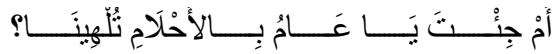

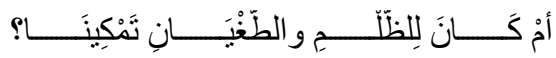

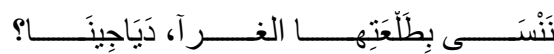

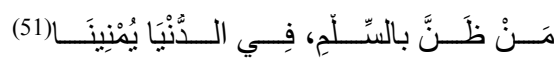

* إيقاع الاستفهام:

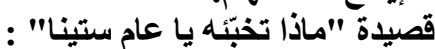

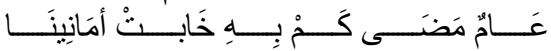

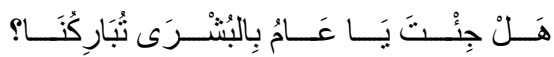

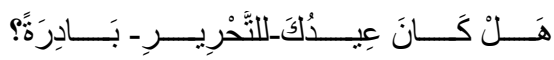

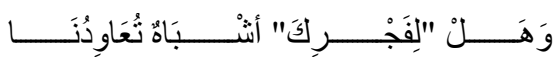

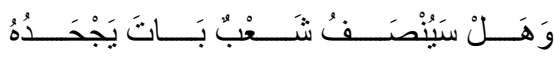

نحس بإيقاعات فيها نوع من الثقل، وهو يتو افق دلاليا مع ما تحمله الأبيات من معان: طول المدة،

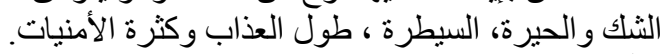

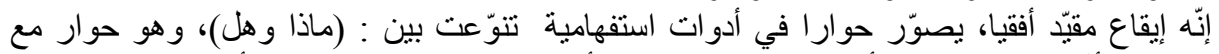

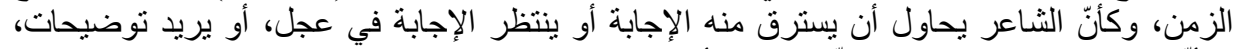

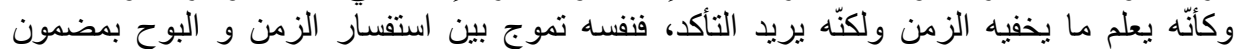

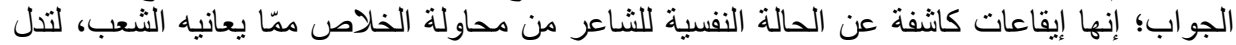

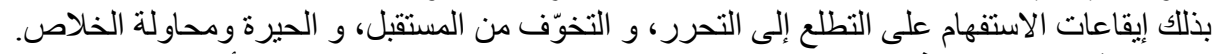

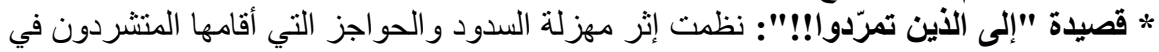

$$
27 \text { جانفي سنة 1960م. فيدة إلى الأين }
$$

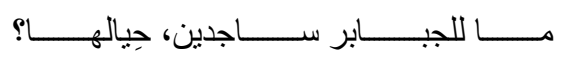

فغــدت تصــبّ علــى الــرؤوس نكالهـــا!؟

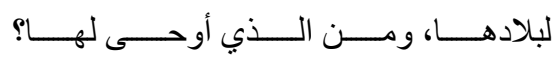

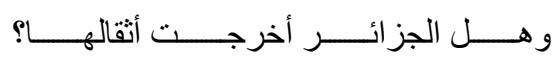

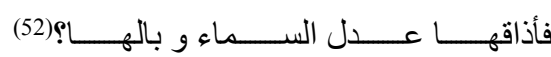

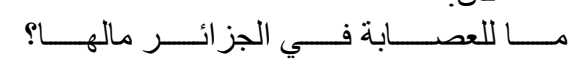

مـــــا للعصـــــاة، علـــــى العتـــــاة تمــــرّد

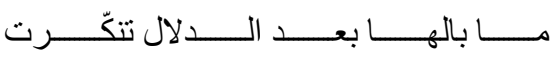

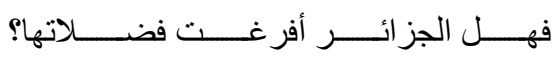

أم هـــل فرنســــا أصـــرفت فـــي عســــها

نحس بايقاع حزين يوحي بحسرة وتأسّف، وقد آزرته أصوات الهمس الكثيرة في الأبيات خاصة السين

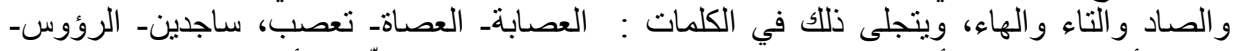

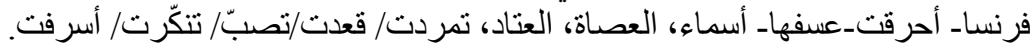


إنها حركة إيقاعية متصاعدة توحي بنوتر وخيية، أو قل بحث عن الإجابة وتزداد حدة في التركيب :

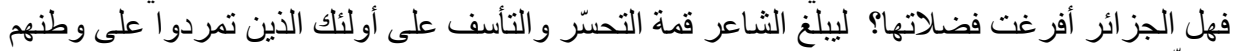

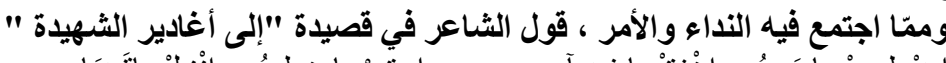

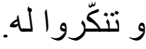

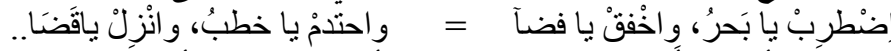

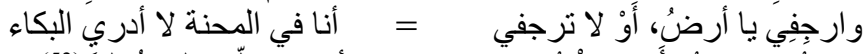

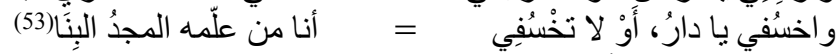

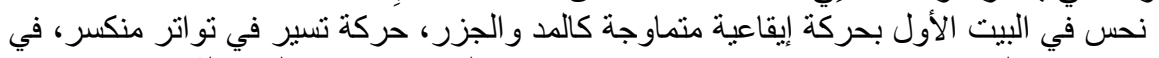

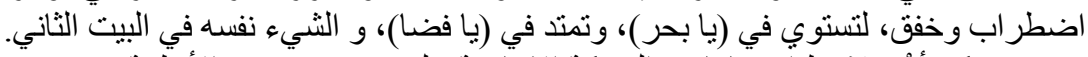

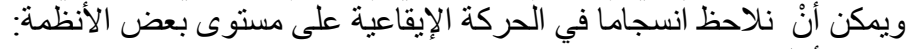

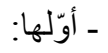

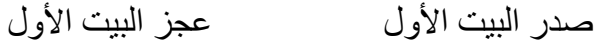

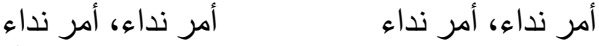

المز اوجة بين الأمر والنداء في توزيع منتظم شكّل إيقاعا متجانسا ، تنتاوب فيه الحركة بتناوب

$$
\begin{aligned}
& \text { تانسين. }
\end{aligned}
$$

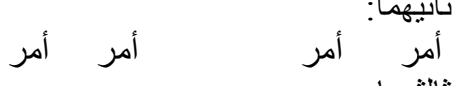

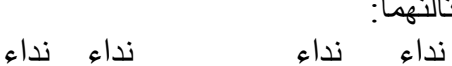

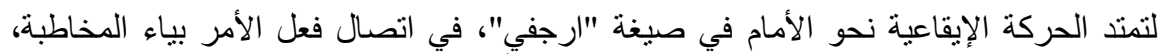

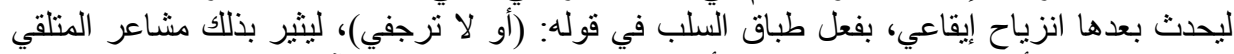

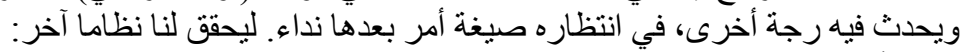

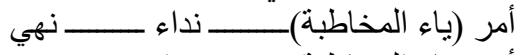

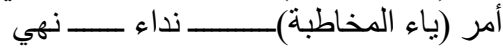

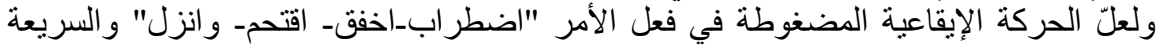

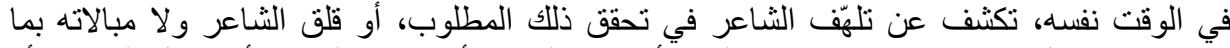

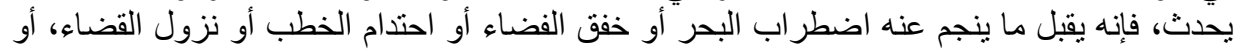

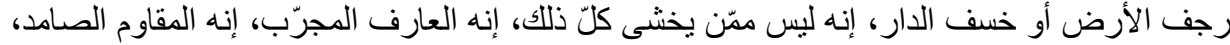

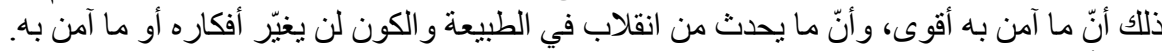

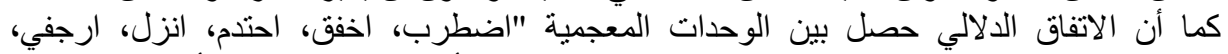

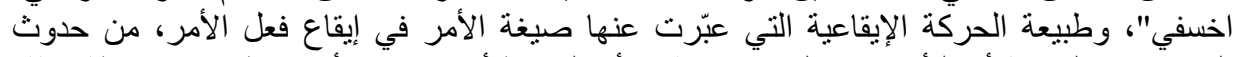

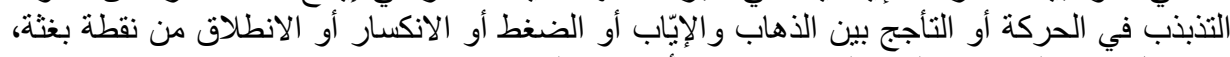

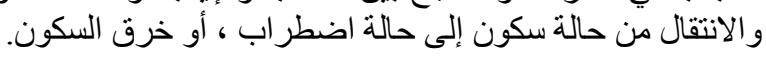

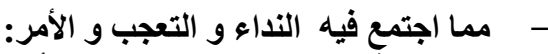
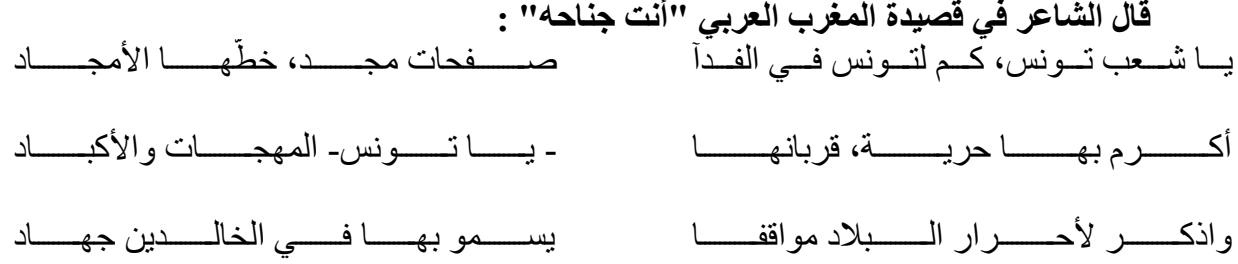

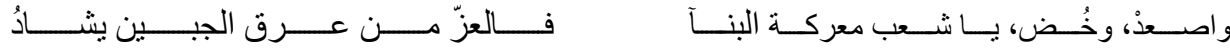


اد

(54) (5)

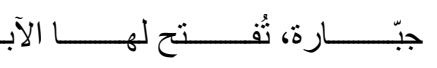

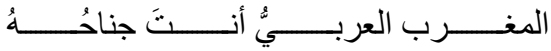

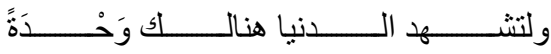

تمتد الحركة الإيقاعية في أسلوب النداء، لتزداد طولا، وكأنه كثرة الإخبار، إغراق في البحث عن

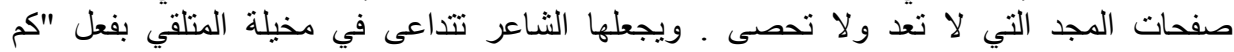

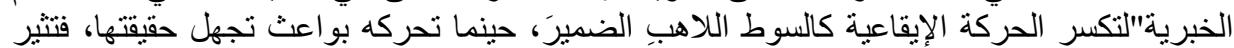
في النفس انفعالا، دهشة وتعجبا، فكانت صيغة التعجب "أفعل بها لإنه المتجانسة دلالية مع كم الخبرية، إنها

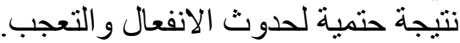

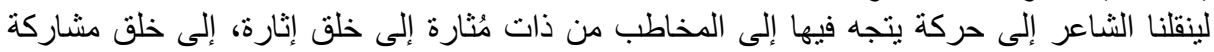

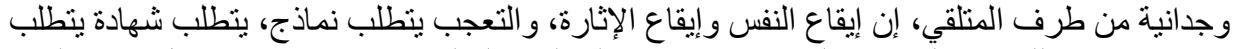
تذكرا و إعمالا للذاكرة، لتستوي الحركة بعدها في الجملتين الفعليتين (يسمو وتمتد) بفعل تقديم الجار الإنا

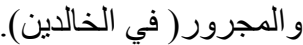

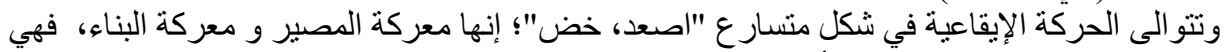

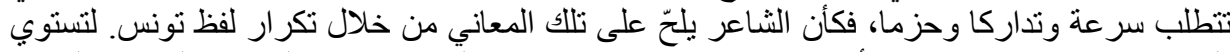

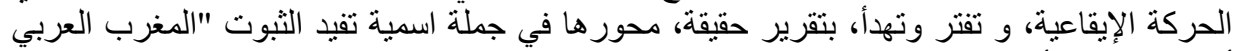

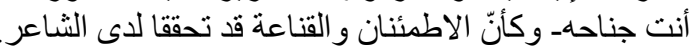

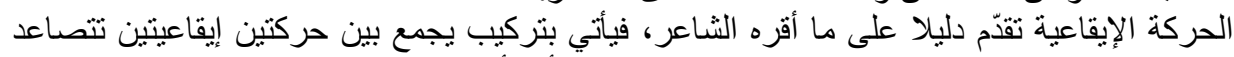

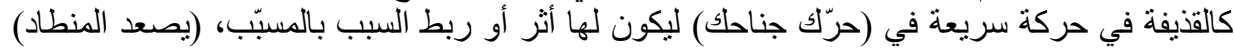

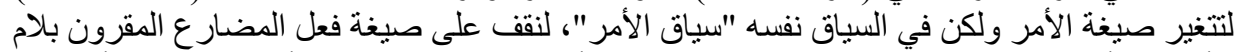

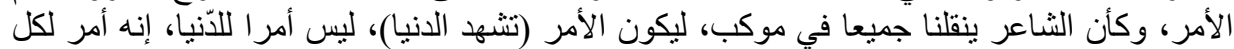

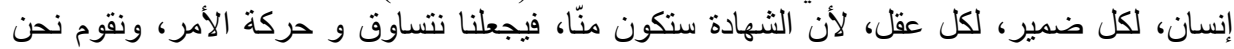
بالثهادة.

وقد عزز ذللك الوحدات اللسانية "وحدة" والنعت جبارة، إنها وحدة لا تتحقّق إلا بنا، أو بالأحرى في ما

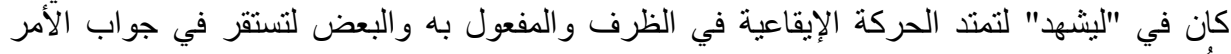

من خلال هذه النماذج المقدمة لإيقاع الخبر والإنشاء في شعر مفدي زكرياء نستنتج أن الحركة الإيقاعية

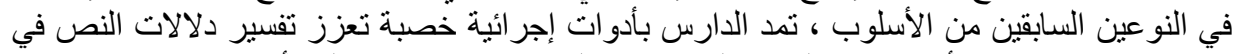

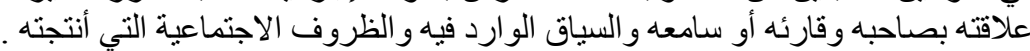

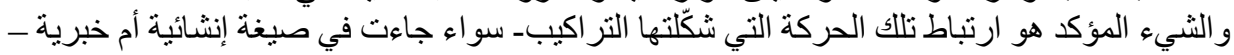

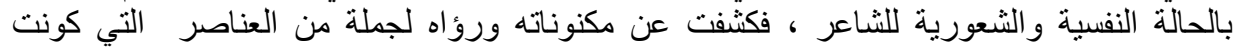

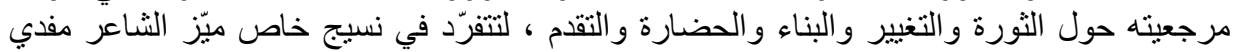
زكرياء عن غيره من الشعر اء على على مستوى التشكيل .

هوامش و إحالات :

1- محمد العياشي، نظرية إيقاع الشعر العربي، المطبعة العصرية، تونس 1976م، صلالات/42.

2 - المرجع نفسهاه ، الصفحة نفسها. 
3- سيد البحراوي: العروض وإيقاع الثعر العربي، محاولة لإنتاج معرفة علمية، مطابع الهيئة المصرية

$$
\text { العامة للكتاب 1993م، ص/لم/ 109، } 110 .
$$

4- مددوح عبد الرحمن: المؤثرات الإيقاعية في لغة الثعر، المؤثرات الإيقاعية في لغة الثُعر، دار المعرفة الجامعية، الإسكندرية 1994م، ص/212، 13. 5-عبد المالك مرناض، في نظرية النقة، دار هومة للطباعة والنشر والتوزيع، الجزائر 2003م، ص/170/n

6- عبد المالك مرتاض، في نظرية النقد، صالإ/169. 7-محمد عبد المطلب، البلاغة و الأسلوبية، مطابع الهيئة المصرية العامة للكتاب، 1984م، صالم/36.35.

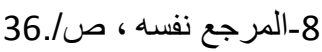

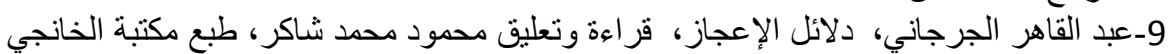

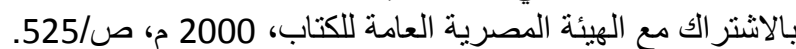

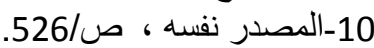

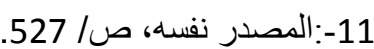

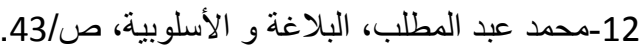

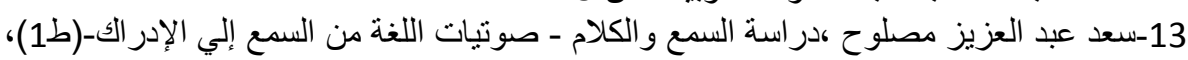

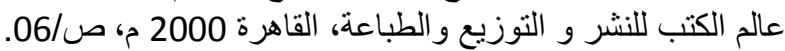

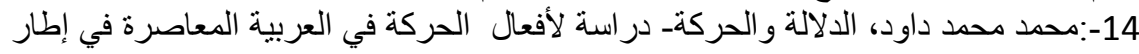

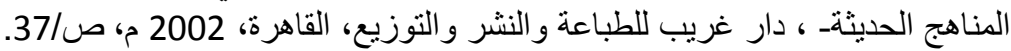

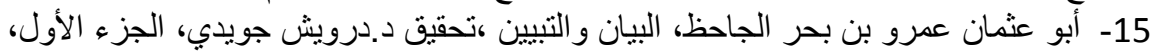

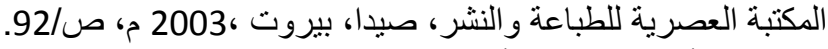

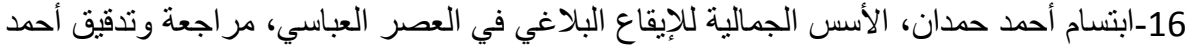

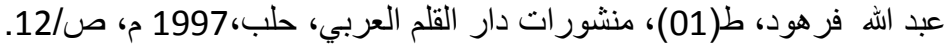

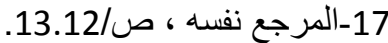

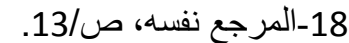

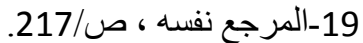

20 - سميرة أبو حمدان : الاسس الجمالية للإيقاع البلاغي في العصر العباسي،ص/2178.

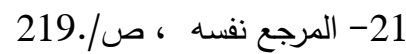

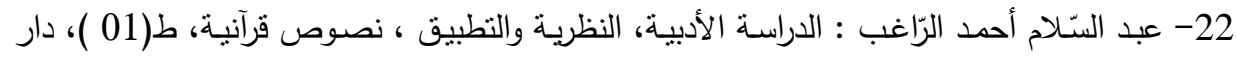

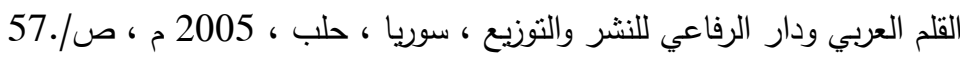
23

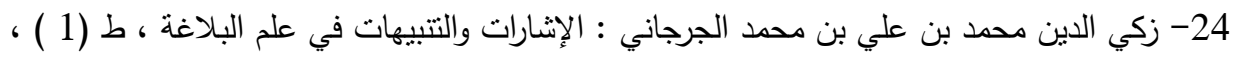

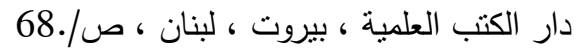




\section{عبد الحميد بوفاس}

25- حسين جمعة : جمالية الخبر والإنشاء ( دراسة بلاغية جمالية نقدية) ، منشورات اتحاد الكتّاب

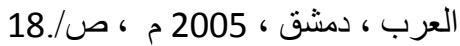

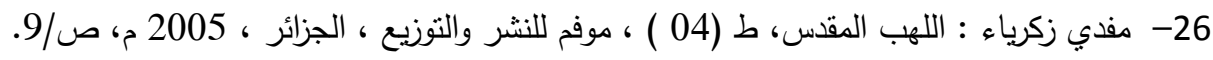

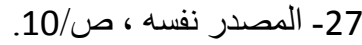

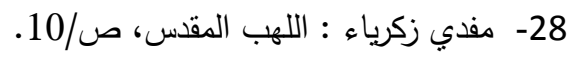

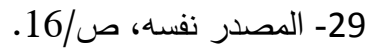

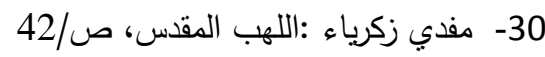

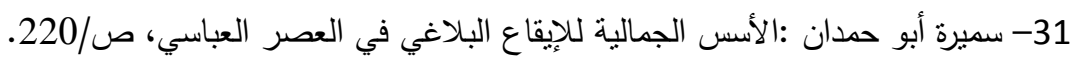

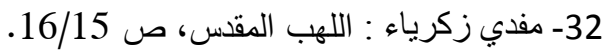

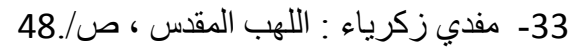

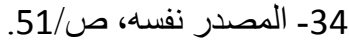

35- - 35 المصدر نفسه، ص 53.53.

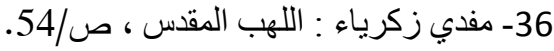

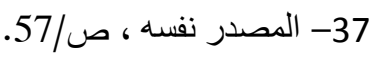

38- المصدر نفسه، ص/63.

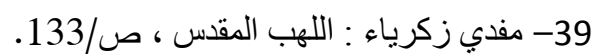

40- 40 - المصدر نفسه ، ص/134.

41 - 4- المصدر نفسه ، ص/133.

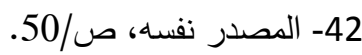

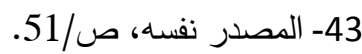

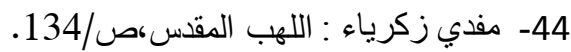

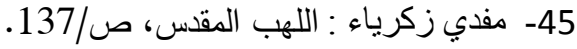

46- الهصدر نفسه ، الصفحة نفسهاء.

47- المصدر نفسه، ص/138.

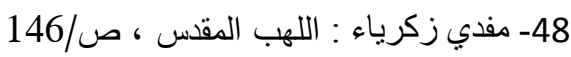

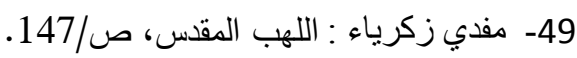

50- المصدر نفسه، ص/148.

51- مفدي زكرياء :اللهب المقس، صن/85/149.

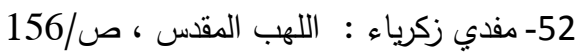

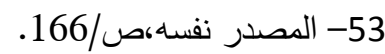

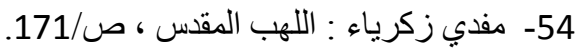




\section{قائمة المصادر والمراجع:}

1) ابتسام أحمد حمدان، الأسس الجمالية للإيقاع البلاغي في العصر العباسي، مراجعة وتدقيق

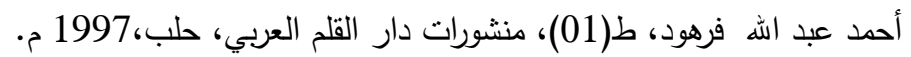

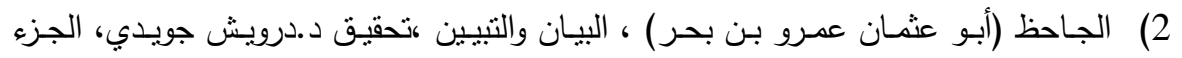

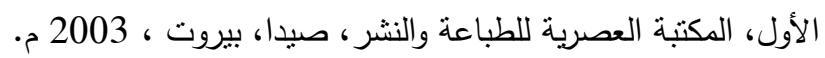

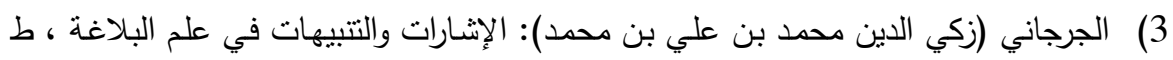

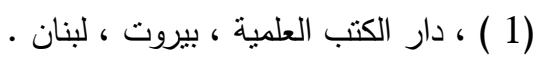

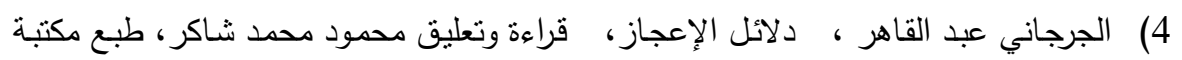
الخانجي بالاشتراك مع الهيئة المصرية العامة للكتاب، 2000 م.

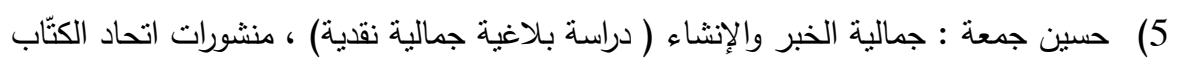

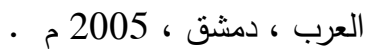

6) سعد عبد العزيز مصلوح ،دراسة السمع والكلام - صسوتيات اللغة من السمع إلي الإدراك(1)، (1)، عالم الكتب للنشر و النوزيع والطباعة، القاهرة 2000 م.

7) سيد البحراوي: العروض وإيقاع الثـعر العربي، محاولة لإنتاج معرفة علمية، مطابع الهيئة المصرية العامة للكتاب 1993م.

8) عبد الستّلام أحمد الرّاغب : الدراسة الأدبية، النظرية والتطبيق ، نصوص قرآنية، ط(01 )،

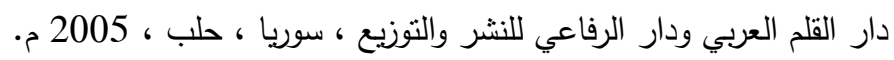

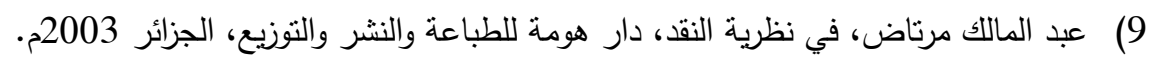

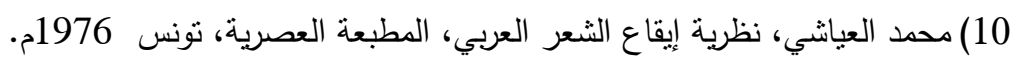

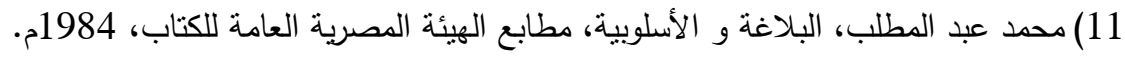

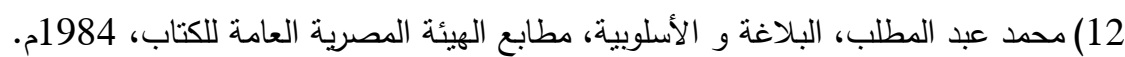

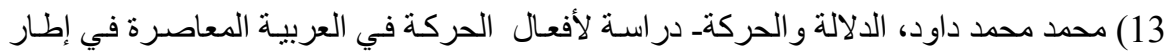

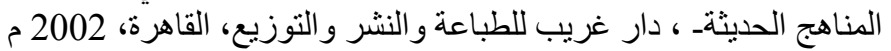

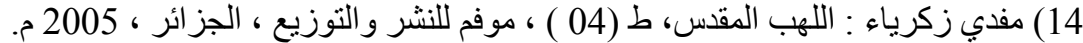

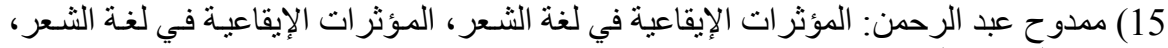

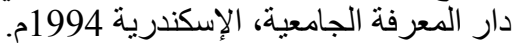

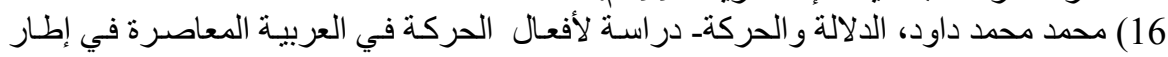

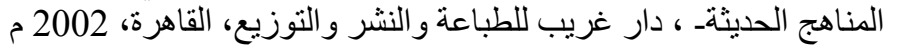

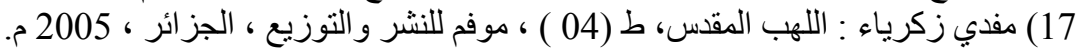

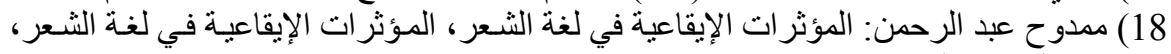

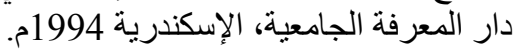

